\title{
Phase I and II Results from Sr and TRU Precipitation Tests
}

by

W. Wilmarth

Westinghouse Savannah River Company

Savannah River Site

Aiken, South Carolina 29808

R. E. Eibling

C. A. Nash

T. B. Edwards

This paper was prepared in connection with work done under the above contract number with the U.S.

Department of Energy. By acceptance of this paper, the publisher and/or recipient acknowledges the U. S.

Government's right to retain a nonexclusive, royalty-free license in and to any copyright covering this paper, along with the right to reproduce and to authorize others to reproduce all or part of the copyrighted paper. 


\section{DISCLAIMER}

This report was prepared as an account of work sponsored by an agency of the United States Government. Neither the United States Government nor any agency thereof, nor any of their employees, makes any warranty, express or implied, or assumes any legal liability or responsibility for the accuracy, completeness, or usefulness of any information, apparatus, product or process disclosed, or represents that its use would not infringe privately owned rights. Reference herein to any specific commercial product, process or service by trade name, trademark, manufacturer, or otherwise does not necessarily constitute or imply its endorsement, recommendation, or favoring by the United States Government or any agency thereof. The views and opinions of authors expressed herein do not necessarily state or reflect those of the United States Government or any agency thereof.

This report has been reproduced directly from the best available copy.

Available for sale to the public, in paper, from: U.S. Department of Commerce, National Technical Information Service, 5285 Port Royal Road, Springfield, VA 22161, phone: (800) 553-6847, fax: (703) 605-6900

email: orders@ntis.fedworld.gov

online ordering: http://www.ntis.gov/ordering.htm

Available electronically at http://www.doe.gov/bridge Available for a processing fee to U.S. Department of Energy and its contractors, in paper, from: U.S. Department of Energy, Office of Scientific and Technical Information, P.O. Box 62, Oak Ridge, TN 37831-0062, phone: (865)576-8401, fax: (865)576-5728 email: reportsladonis.osti.gov 


\section{DISCLAIMER}

Portions of this document may be illegible in electronic image products. Images are produced from the best available original document. 
BNF-003-98-0180

Phase I and II Results from Sr and TRU Precipitation Tests

W. R. Wilmarth

R. E. Eibling

C. A. Nash

T. B. Edwards

September 15, 1999
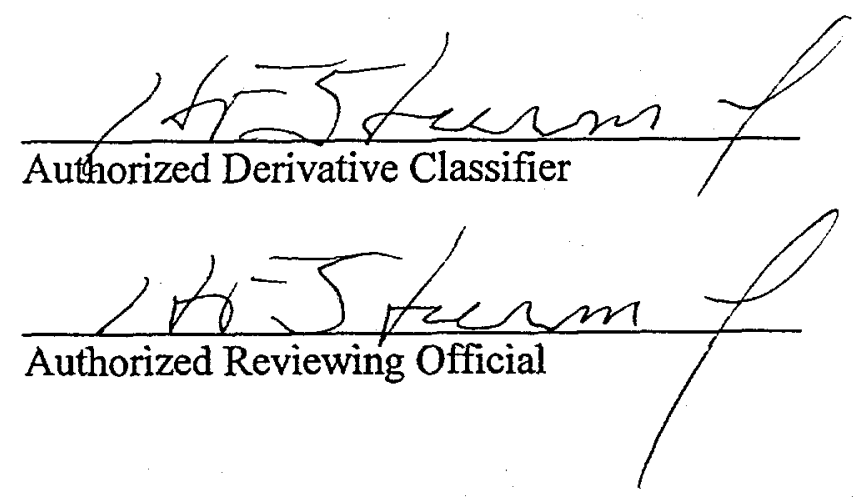

Westinghouse

Savannah River Company

Alken, SC 29808

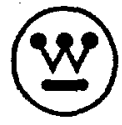

BNFL

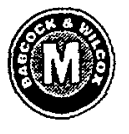




\section{Phase I and II Results from Sr and TRU Precipitation Tests}

W. R. Wilmarth

R. E. Eibling

C. A. Nash

T. B. Edwards

September 15, 1999 


\section{DISCLAIMER NOTICE}

This report was prepared by Westinghouse Savannah River Company, Inc. (WSRC) on behalf of the U.S. Department of Energy (DOE), as an account of work sponsored by BNFL, Inc. Neither WSRC, DOE, the U.S. Government, or any person acting on their behalf makes any warranty, express or implied, or assumes any legal liability or responsibility for the accuracy, completeness, or usefulness of any information, apparatus, product, or process disclosed, or represents that its use would not infringe privately owned rights. Reference herein to any specific commercial product, process, or service by trade name, trademark, manufacturer, or otherwise, does not necessarily constitute or imply its endorsement, recommendation, or favoring by WSRC, DOE, or the U.S. Government. The views and opinions of authors expressed herein do not necessarily state or reflect those of WSRC, DOE, or the U.S. Government.

Savannah River Technology Center Westinghouse Savannah River Company Aiken, SC 29808 
W. R. Wilmarth

BNF-003-98-0180

Page 3 of 33

\section{Table of Contents}

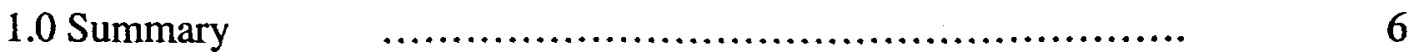

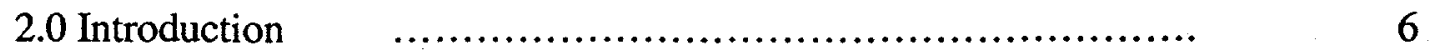

3.0 Experimental $\quad$............................................... : $\quad 7$

3.1 Phase 1 ............................................... 7

Screen Tests to Determine Variables that Influence Filterability 3.2 Phase 1B:

Revision to AN-107 Simulant Composition

3.3 Phase 2:

Influence of Organic Complexation and Filterability

4.0 Discussion $\quad$............................................... $\quad 12$

4.1 Phase 1 .................................................

4.2 Fe Titration $\quad$............................................

4.3 Confirmatory Tests $\quad$................................

4.4 Organic Grouping $\quad$...................................

Single Effects Tests

4.5 Real Waste Scoping Tests................................

4.6 Phase 2 .............................................

5.0 Conclusions $\quad$................................................. $\quad 28$

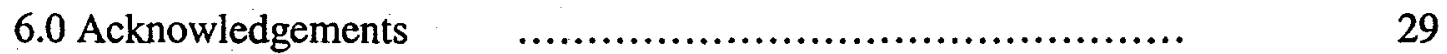

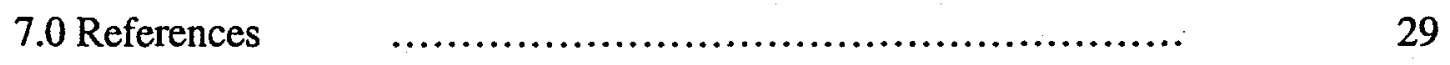

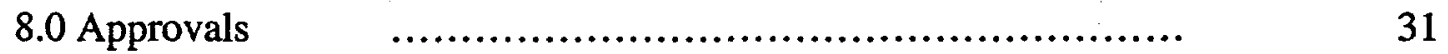




\section{List of Tables}

Table 1: 30-Beaker Test

Table 2: Experimental Design

for 25-Beaker Test

Table 3. Filterability Data

12 from Phase 1 Tests

Table 4. Statistical Analysis

Results from Filtration Data in Phase 1 Tests

Table 5. Lanthanide Concentrations

Table 6. Statistical Analysis Results

Table 7. Al Concentrations in Phase 1 Tests

Table 8. Experimental Matrix for Confirmatory Tests

Table 9. Statistical Analysis of the Filtration Data from Confirmatory Tests

Table 10. Lanthanide Concentrations $(\mathrm{mg} / \mathrm{L})$ in Confirmatory Tests

Table 11. Statistical Analysis Result from the Confirmatory Tests

Table 12. Organic Group Single Effects Tests

Table 13. DFs from Real Waste Tests of AN-102 Phase 2 Beaker Tests

Table 15. Regression Results from Phase 2 Filtration Tests

Table 16. Decontamination Factors from Phase 2 Tests 


\section{List of Figures}

Figure 1. Experimental Apparatus for $\mathrm{Sr} / \mathrm{TRU}$ Precipitation 8

Figure 2. Neodymium DF as a Function of Sodium Level and Temperature

Figure 3. Fe Titration of AN-107 Simulant 17

Figure 4. Fe Titration of Revised AN-107 Simulant 17

Figure 5. AN-102 Simulate Supernate, Sr/TRU Filtrate and St/TRU Precipitate

Figure 6. Filtrate Mass versus Iron Concentration in Confirmatory Tests

Figure 7. Sodium and Iron Statistical Plots for DF in Confirmatory Tests

Figure 8. Filtrate Flux Results from Organic Grouping Tests

Figure 9. Filtration Data from Real Waste Tests

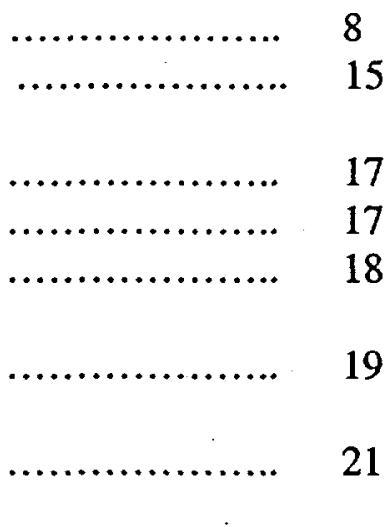
with AN-107 Samples

Figure 10. Statistical Plot for the Gluconate Group and the Sodium Levels

Figure 11. Statistical Plot of Sr DF Data 


\title{
Phase 1 and 2 Results from Sr/TRU Precipitation Tests
}

\author{
W. R. Wilmarth, R. E. Eibling, and C. A. Nash \\ Waste Processing Technology Section \\ T. B. Edwards \\ Statistical Consulting Section \\ Savannah River Technology Center \\ Westinghouse Savannah River Company
}

\subsection{Summary}

The BNFL removal processes for strontium and transuranic components from the AN102 and $\mathrm{AN}-107$ supernate originally proposed are co-precipitation methods. In initial testing, the precipitates formed during the strontium and ferric nitrate additions were not filterable. Two series of statistically designed tests examined over a dozen variables that possibly could affect the filterability of the precipitate and the associated decontamination of the species of interest. The conclusions from these tests are:

- Filterability is influenced by the amount of ferric ion added to co-precipitate the actinide elements and the amount of at least one organic component in the gluconate grouping (gluconate, glycolate and citrate).

- Hydroxide ion concentration did not affect filterability.

- Filter fluxes in sheared environments with ferric ion present are too low for cross flow filtration to be successful. Investigations are currently focused on alternative precipitating agents.

- The sodium ion concentration and level of organic complexants influence decontamination of the supernate.

- Decontamination factors measured for americium using maximum iron nitrate addition were not sufficient to assure required decontamination.

- Testing with real waste (AN-102) showed higher filterability than previous work along with equivalent decontamination.

- Initial simulant composition included higher sodium gluconate levels than real waste based on iron chemistry. Test results indicate that iron and gluconate form a soluble complex with a 1:1 stoichiometry.

\section{$\underline{2.0 \text { Introduction }}$}

Strontium and the actinide elements U, Pu and Am are present in the High Level Liquid Waste in the Hanford tanks AN-102 and AN-107 due to the presence of complexing agents used in the processes within B Plant. ${ }^{1}$ The mission of B Plant was to recover Sr90 from Purex Acidified Sludge (PAS). Hydroxyethylene diamine triacetic acid (HEDTA), ethylene diamine tetraacetic acid (EDTA), and citric acid were added to complex many of the di- and trivalent metals in order to prevent their extraction from the 
aqueous phase into the organic solvent. The tributylphosphate-normal paraffin hydrocarbon solvent was then washed in several stages before recycle. Dilute glycolic acid was used to wash sodium from the solvent. After nitric acid washes to remove desired product the organic phase was washed with sodium gluconate and excess hydroxide to remove yttrium and uranium.

The proposed BNFL removal processes for strontium and transuranic components from the AN-102 and AN-107 supernate are co-precipitation methods. In Part A, tests were performed to decontaminate real waste samples using natural strontium nitrate in an isotopic dilution and ferric nitrate to co-precipitate the actinides. ${ }^{2-5}$ This work was based on earlier investigations by Herting ${ }^{6}$ and Orth, et al. ${ }^{7}$ In general, the results of the experiments indicated a successful decontamination for $\mathrm{Sr}-90$ and the actinides. However, the liquid/solid separation was accomplished by centrifugation. The resulting precipitates could not be filtered. In scoping tests, $\mathrm{Nash}^{8}$ found that precipitate filterability improved if strontium was added before iron.

The objective of this work was to examine several factors that potentially influence filtration of the Sr/TRU precipitate. The research was performed using statistically designed experiments in a three-phased approach. Variables in the first non-radioactive phase included temperature, sodium ion concentration, hydroxide ion concentration, strontium concentration and total amount, ferric ion concentration and method of addition. Organic components in Envelope $\mathrm{C}$ are the complexants that increase the solubility of the strontium and that of the actinides and are thought to alter the filterability of the Sr/TRU precipitate. A second set of statistically defined experiments examined the influences of each of the organic components in Envelope C simulant spiked with $\mathrm{Sr}-85$, Pu-239 and Am-241 tracers. The results of these phases of tests are reported. The third phase of statistically designed experiments examined permanganate as a precipitation reagent for the transuranic elements instead of ferric ion. A separate report will address the results from the third phase of experiments.

\subsection{Experimental}

\subsection{Phase 1: Screening Tests to Determine Variables that Influence Filterability}

Phase 1 examined several variables that possibly effect the filterability of the Sr/TRU precipitate produced from the AN-107 simulant (See composition in Appendix 1). ${ }^{9}$ The nine factors investigated were: sodium ion, hydroxide ion, and aluminum concentrations; temperature; the total amount of strontium added to the system; the strontium ion concentration of the reagent solution; the total amount of iron added to the system; the iron concentration of reagent solution; and method of addition. The sodium, hydroxide and aluminum concentrations spanned the AN-102 and AN-107 tank chemistries. Typical concentrations of the organic complexants were used. The organic complexants were ethylenediaminetetraacetic acid (EDTA), citric acid, glycolic acid, N-(2hyroxyethyl)ethylene ethylenediaminetetraacetic acid (HEDTA), and iminodiacetic acid 
(IDA). Lanthanum, cerium and neodymium were used as surrogates for plutonium and americium.

Approximately $50 \mathrm{~mL}$ of the simulant was placed into a $200-\mathrm{mL}$ beaker. The simulant had been adjusted to the hydroxide and aluminum concentration specified in Table 1. The solution was stirred with a magnetic stirrer and then heated to the required temperature in a water bath on a heater/stirrer plate. An aliquot of the precipitating agent (strontium nitrate or ferric nitrate) was delivered to the beaker using a $\mathrm{Kd}$ syringe pump, model 100 , at a delivery rate of $0.5 \mathrm{~mL} / \mathrm{min} .{ }^{10}$ The precipitate slurry was stirred for 15 minutes at temperature prior to the addition of the second precipitating agent. After the second addition, the slurry was stirred for 15 minutes, allowed to cool to room temperature and filtered through a 0.45 -micron filter. The filtrate was collected for 1 minute and weighed or volumetrically measured. The time intervals used in these experiments are shorter than those used during the previous work. However, sufficient decontamination should occur during the first 15 minutes to allow for analysis and efficient completion of the tests. After the samples have cooled, the remaining slurry was filtered. Samples were submitted to the Analytical Development Section of SRTC for analyses. "These analyses included elemental analysis by Inductively Coupled Plasma Emission spectroscopy, ${ }^{12}$ Inductively Coupled Plasma - Mass Spectrometry, ${ }^{13}$ gamma spectroscopy; ${ }^{14}$ liquid scintillation analysis for strontium- $90,{ }^{15}$ and alpha pulse height analysis. ${ }^{16}$ Shown in Figure 1 is the experimental setup used in the real waste tests. This experimental protocol was used in each phase of Sr/TRU precipitation testing.

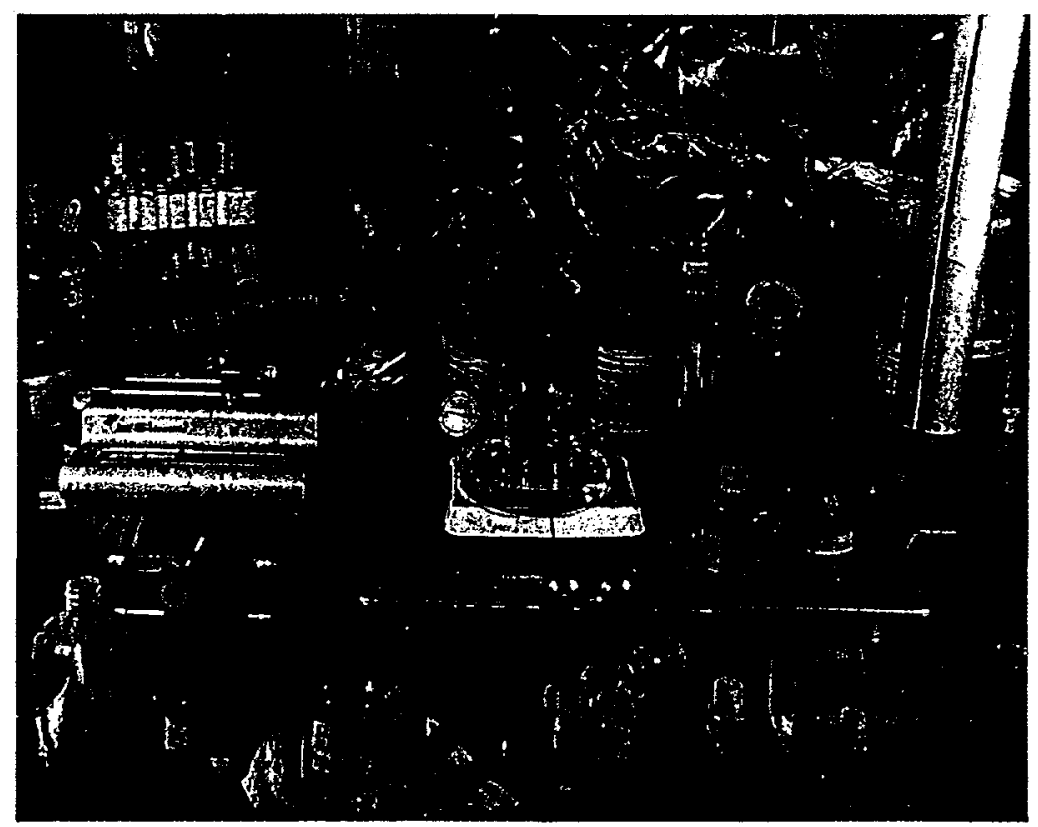

Figure 1. Experimental Apparatus for Sr/TRU Precipitation 
The objective of Phase 1 was to determine the primary variables that influence filterability. $\mathrm{JMP}^{17}$ was used to generate the fractional factorial design that appears in Table 1. Software validation ${ }^{18}$ was performed on the JMP software. The statistical design allowed for all primary variables to be found. Filterability is the primary response variable. However, other responses are important to the overall Hanford flowsheet. Included in these are the fates of sulfate, carbon and aluminate. Analysis of the filtrate was performed to measure these species. The amount in the precipitate was calculated by difference.

The aliasing structure for these trials indicated that most of these 9 main effects are confounded with two-way interaction terms in this screening experiment. The distinction between a significant main effect and a possible two-way interaction will be facilitated by the Phase 2 tests.

As indicated in Table 1, a center point was run as part of each day's processing with the method of iron addition being alternated between "drop" and "needle." A minimum of 2 center points was performed, one by each method of iron addition. "Drop" refers to dropwise addition of reagent and "needle" refers to the use of a fine hypodermic needle with its tip submerged in the agitated solution. Needle would introduce a fine thread of reagent into the mixture in contrast to the dropwise method.

Table 1: 30-Beaker Test

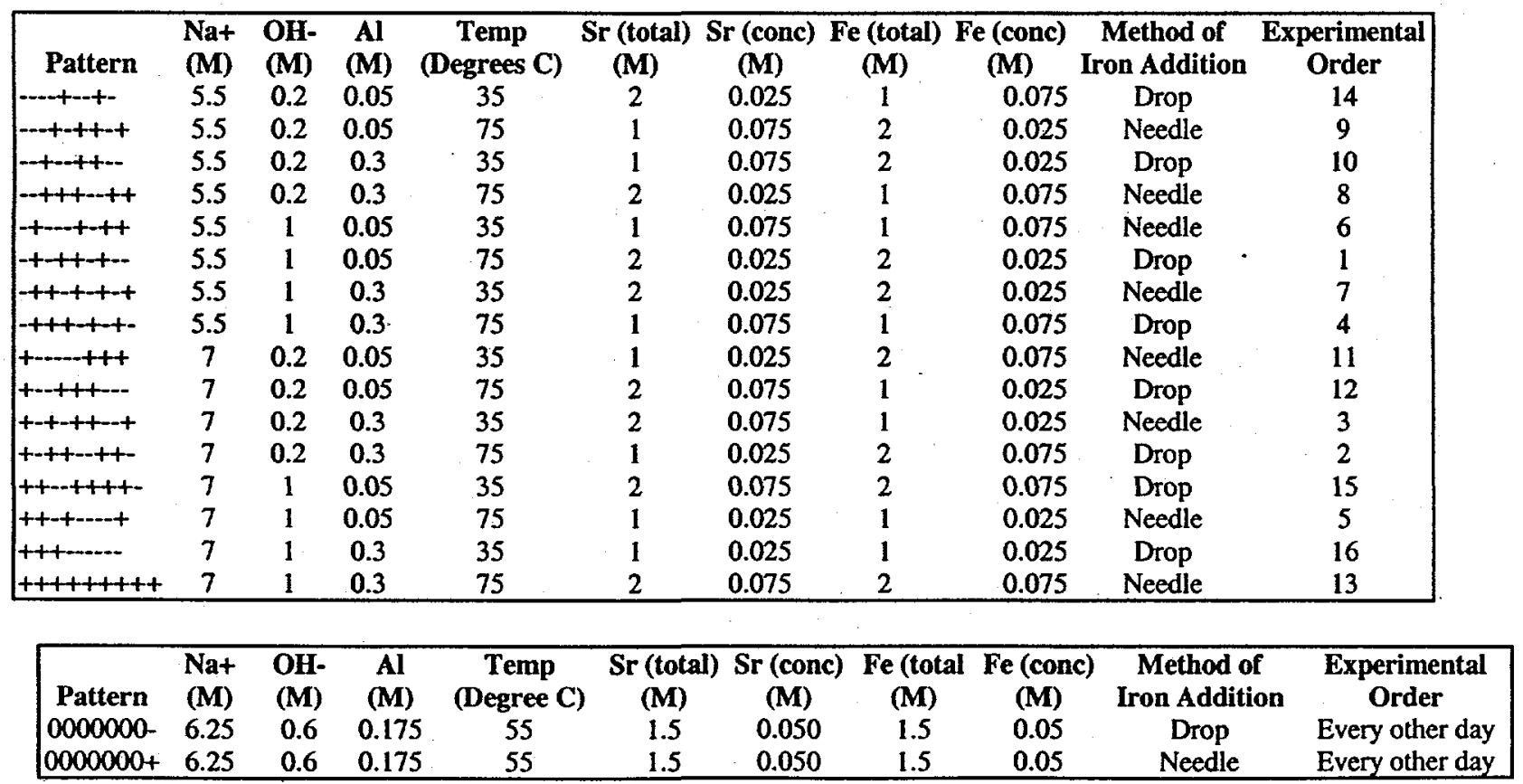




\subsection{Phase 1B: Revision to AN-107 Simulant Composition}

SRTC personnel reviewed Phase 1 results with the BNFL technical representative during December 1998. Data review indicated that the gluconate level in the simulant was too high. As a result of these discussion three small sets of tests will be conducted prior to the actual start of the 25-Beaker tests. These three sets of tests are:

- Iron Titration - The objective of this test was to determine the stoichiometry of the Fe-gluconate complex. In this test, ferric nitrate was incrementally added to a fixed gluconate solution. The amount of ferric ion in solution was measured by ICP-ES.

- An initial grouping of organic complexing agents for the 25-Beaker tests was recommended. This grouping is shown in Table 2. After the Fe titration experiment provided the stoichiometry of the Fe-gluconate complex, the simulant was revised. Single effects tests were performed on the nominal simulant. Both filterability and DF were measured.

- A series of confirmatory tests was performed using the revised simulant recipe. The objective of these tests was to span the variables which were shown to be statistically significant. Filterability and a decontamination factor based on $\mathrm{La}, \mathrm{Ce}$, and $\mathrm{Nd}$ were measured.

- Test the sample of AN-102 for filterability and decontamination. A set of three test was performed to include: a test with the precipitating reagent in the method used in Part A; a test reversing the order of addition; and a test in which the precipitate formed with the order reversed followed by shearing in a blender. These tests were conducted to determine if the model used to predict filterability from the AN-107 simulant would be valid for the $\mathrm{AN}-102$ radioactive waste.

\subsection{Phase 2: Influence of Organic Complexation and Filterability}

The BNFL technical representative approved the Phase 2 matrix before SRTC personnel proceeded with testing. The objective of Phase 2 was to determine the influence of each of the organic complexants has on the filterability of the $\mathrm{Sr} / \mathrm{TRU}$ precipitate. The levels for each primary variable were the same as in Phase 1 . The coded levels $(1,0,-1)$ of organic complexants were established to span the range of their concentrations measured in the actual waste (AN-102 and AN-107). 
Table 2: Experimental Design for 25-Beaker Test

\begin{tabular}{|c|c|c|c|c|c|c|}
\hline Pattern & $\mathrm{Na}$ & Al & $\mathrm{OH}$ & $\begin{array}{c}\mathrm{Fe} \\
\text { Conc. }\end{array}$ & \begin{tabular}{|c|} 
Gluconate \\
Citrate \\
Glycolate \\
\end{tabular} & EDTA/HEDTA/IDANTA \\
\hline - -.--- & -1 & -1 & -1 & -1 & -1 & -1 \\
\hline---++++- & -1 & -1 & -1 & 1 & 1 & 1 \\
\hline$--+-++-t$ & -1 & -1 & 1 & -1 & -1 & 1 \\
\hline--++-++ & -1 & -1 & 1 & 1 & 1 & -1 \\
\hline$-+\cdots+++$ & -1 & 1 & -1 & -1 & 1 & -1 \\
\hline$-t-t-t-t$ & -1 & 1 & -1 & 1 & -1 & 1 \\
\hline$-++\cdots++$ & -1 & 1 & 1 & -1 & 1 & 1 \\
\hline$+t++\cdots$ & -1 & 1 & 1 & 1 & -1 & -1 \\
\hline$+\cdots+++$ & 1 & -1 & -1 & -1 & 1 & 1 \\
\hline+-++--+ & 1 & -1 & -1 & 1 & -1 & -1 \\
\hline+-+-+-+- & 1 & -1 & 1 & -1 & 1 & -1 \\
\hline$+-++-t--$ & 1 & -1 & 1 & 1 & -1 & 1 \\
\hline$++\cdot-+t \cdot \cdot$ & 1 & 1 & -1 & -1 & -1 & 1 \\
\hline++-+--+- & 1 & 1 & -1 & 1 & 1 & -1 \\
\hline+++---+ & 1 & 1 & 1 & -1 & -1 & -1 \\
\hline$t++++t+t$ & 1 & 1 & 1 & 1 & 1 & 1 \\
\hline
\end{tabular}

Organic levels based on $8.7 \mathrm{M}$ sodium ion in starting salt solution concentrations were:

$\underline{\text { Level }}$

$-1$

0

1
Organic Group

EDTA

HEDTA

NTA

IDA

Glycolate

Citrate

Gluconate

EDTA

HEDTA

NTA

IDA

Glycolate

Citrate

Gluconate

EDTA

HEDTA

NTA

IDA

Glycolate

Citrate

Gluconate
Concentration (M)

0.0075

0.0078

0.0

0.0375

0.07

0.0128

0.0

0.022

0.023

0.004

0.113

0.21

0.038

0.009

0.037

0.039

0.0073

0.188

0.35

0.064

0.018 
Iron concentration levels were $1(0.1 \mathrm{M}), 0(0.06 \mathrm{M}),-1(0.02 \mathrm{M})$. Additionally, a test was conducted with an iron concentration of $0.075 \mathrm{M}$. Tests were conducted at $50^{\circ} \mathrm{C}$. Plutonium-239 and americium-241 were spiked into the simulated salt solutions. The gamma-emitting Sr-85 was used instead of Sr-90. As in Phase 1, filterability is the primary response. Laboratory notebook WSRC-NB-97-63 contains data obtained during these tests and the procedures used. Personnel used routine analytical protocol for the samples in this report. ${ }^{11}$

\subsection{Discussion}

\subsection{Phase 1 (30 Beaker Tests)}

In addition to the experimental matrix, Table 3 contains the filtration results measured in the first phase of testing. The filtrate flux is provided in terms of weight of filtrate (g) per second of filtration time. As mentioned in the experimental section, the filtrate was collected for the first minute of filtration and then weighed. In all experiments, the $\mathrm{Sr} / \mathrm{TRU}$ precipitate formed by stepwise addition of strontium nitrate and ferric nitrate was filterable. The filtrate flux ranged from 0.18 to $2.6 \mathrm{~g} / \mathrm{s}$. The filtrates were very highly colored being very dark red.

Table 3. Filterability Data from Phase 1 Tests

\begin{tabular}{|c|c|c|c|c|c|c|c|c|c|c|c|}
\hline Pattern & $\begin{array}{l}\mathrm{Nat} \\
(\mathrm{M})\end{array}$ & $\begin{array}{l}\mathrm{OH}- \\
(\mathrm{M})\end{array}$ & $\begin{array}{l}\mathrm{Al} \\
(\mathrm{M})\end{array}$ & $\begin{array}{l}\text { Temp } \\
\left({ }^{\circ} \mathrm{C}\right)\end{array}$ & $\begin{array}{c}\text { Sr (total) } \\
\text { (M) }\end{array}$ & $\begin{array}{l}\mathrm{Sr} \text { (conc) } \\
\text { (M) }\end{array}$ & $\begin{array}{c}\text { Fe (total) } \\
\text { (M) }\end{array}$ & $\begin{array}{c}\text { Fe (conc) } \\
(M)\end{array}$ & $\begin{array}{l}\text { Method of } \\
\text { Iron Addition }\end{array}$ & $\begin{array}{l}\text { Exp. } \\
\text { Order }\end{array}$ & Filtrate Flux $9(\mathrm{~g} / \mathrm{s})$ \\
\hline---+-+ & 5.5 & 0.2 & 0.05 & 35 & 2 & 0.025 & 1 & 0.075 & Drop & 14 & 1.6409 \\
\hline---+-++-+ & 5.5 & 0.2 & 0.05 & 75 & 1 & 0.075 & 2 & 0.025 & Needle & 9 & 1.3552 \\
\hline-+-++- & 5.5 & 0.2 & 0.3 & 35 & 1 & 0.075 & 2 & 0.025 & Drop & 10 & 0.1799 \\
\hline-+++-++ & 5.5 & 0.2 & 0.3 & 75 & 2 & 0.025 & 1 & 0.075 & Needle & 8 & 0.1872 \\
\hline++-++ & 5.5 & 1 & 0.05 & 35 & 1 & 0.075 & 1 & 0.075 & Needle & 6 & 0.6269 \\
\hline+++++ & 5.5 & 1 & 0.05 & 75 & 2 & 0.025 & 2 & 0.025 & Drop & 1 & 0.5607 \\
\hline++-++ & 5.5 & 1 & 0.3 & 35 & 2 & 0.025 & 2 & 0.025 & Needle & 7 & 2.6071 \\
\hline+++++- & 5.5 & 1 & 0.3 & 75 & 1 & 0.075 & 1 & 0.075 & Drop & 4 & 0.2727 \\
\hline$+-+++t$ & 7 & 0.2 & 0.05 & 35 & 1 & 0.025 & 2 & 0.075 & Needle & 11 & 0.9539 \\
\hline++++- & 7 & 0.2 & 0.05 & 75 & 2 & 0.075 & 1 & 0.025 & Drop & 12 & 0.8984 \\
\hline+-+++-+ & 7 & 0.2 & 0.3 & 35 & 2 & 0.075 & 1 & 0.025 & Needle & 3 & 0.3007 \\
\hline+-++--++- & 7 & 0.2 & 0.3 & 75 & 1 & 0.025 & 2 & 0.075 & Drop & 2 & 0.3254 \\
\hline++--++++ & 7 & 1 & 0.05 & 35 & 2 & 0.075 & 2 & 0.075 & Drop & 15 & 0.317 \\
\hline$+++\cdots+$ & 7 & 1 & 0.05 & 75 & 1 & 0.025 & 1 & 0.025 & Needle & 5 & 0.8098 \\
\hline+++- & 7 & 1 & 0.3 & 35 & 1 & 0.025 & 1 & 0.025 & Drop & 16 & 1.6904 \\
\hline$++++++++t$ & 7 & 1 & 0.3 & 75 & 2 & 0.075 & 2 & 0.075 & Needle & 13 & 0.8235 \\
\hline 0000000 & 6.25 & 0.6 & 0.175 & 55 & 1.5 & 0.05 & 1.5 & 0.05 & Drop & $\begin{array}{l}\text { Every other } \\
\text { day }\end{array}$ & 1.5128 \\
\hline $0000000+$ & 6.25 & 0.6 & 0.175 & 55 & 1.5 & 0.05 & 1.5 & 0.05 & Needle & $\begin{array}{c}\text { Every other } \\
\text { day }\end{array}$ & 1.877 \\
\hline
\end{tabular}


The results from the statistical analysis of the filtration data are provided in Table 4 . The JMP Statistical program, version 3.2.2 was used to fit the filtrate flux data to a linear function of the nine variables. The values shown in Table 4 are the model estimates (coefficients) of the linear response model, the standard errors of the estimates, the statistical t ratio's, and the significance levels (i.e., Prob $>|t|$ ). For a parameter to be statistically significant, the significance level should be less than or equal to 0.05 . The results from the filtration data from the Phase 1 tests show that no parameter studied was statistically significant for filterability. It had been thought that the bulk iron or strontium concentration would affect the filterability of the Sr/TRU precipitate. However, none of the nine parameters tested were significant at $95 \%$ confidence level. Actually, none of the parameters were close to being significant with the feed strontium concentration ( $[\mathrm{Sr}]_{\text {conc }}$ ) significant only at slightly greater than $75 \%$. In addition, the precipitates from these tests were predominantly white to cream colored. This color indicates that Fe is not participating in the precipitation step. The lack of iron in the precipitate along with lower than expected lanthanide decontamination were factors that lead to the post Phase 1 tests discussed earlier.

Table 4. Statistical Analysis Results from Filtration Data in Phase 1 Tests

\begin{tabular}{lclcl}
\hline Term & Estimate & Std Error & t Ratio & Prob $>|t|$ \\
& & & & \\
Intercept & 2.61 & 2.04 & 1.28 & 0.231 \\
$\mathrm{Na}+$ & -0.11 & 0.26 & -0.42 & 0.685 \\
OH- & 0.29 & 0.49 & 0.60 & 0.566 \\
Al & -0.39 & 1.57 & -0.25 & 0.810 \\
Temp & -0.01 & 0.01 & -0.98 & 0.351 \\
Sr(total) & 0.14 & 0.39 & 0.36 & 0.729 \\
Sr(conc) & -10.0 & 7.83 & -1.28 & 0.234 \\
Fe(total) & 0.09 & 0.39 & 0.22 & 0.829 \\
Fe(conc) & -8.14 & 7.83 & -1.0 & 0.326 \\
& & & & \\
\hline
\end{tabular}

The soluble lanthanide ( $\mathrm{La}, \mathrm{Ce}$, and Nd) concentrations were measured by ICP-ES in the initial simulant at nominally $8.8 \mathrm{M}$ sodium ion concentration and in the filtrate following the chemical adjustments ( $\mathrm{Na}, \mathrm{Al}$, and $\mathrm{OH}$ ) and the addition of the precipitating agents $\mathrm{Sr}$ and Fe nitrates. The decontamination factor for each lanthanide was computed and the factors are shown in Table 5. Decontamination factors ranged from essentially no decontamination $(\mathrm{DF}=1.1)$ to 2.7 . 
Table 5. Lanthanide Concentrations (mg/L) measured in Phase 1 Tests

\begin{tabular}{ccccccc}
\hline La & La DF & Ce & Ce DF & Nd & Nd DF \\
21.1 & 1.7 & 41.19 & 1.6 & 20.39 & 1.6 \\
19.73 & 1.8 & 46.97 & 1.4 & 19.17 & 1.7 \\
16.17 & 2.2 & 32.63 & 2.1 & 15.61 & 2.1 \\
18.63 & 1.9 & 39.49 & 1.7 & 18.49 & 1.8 \\
16.35 & 2.2 & 33.79 & 2.0 & 16.73 & 2.0 \\
19.36 & 1.9 & 38.77 & 1.7 & 20.05 & 1.7 \\
13.59 & 2.7 & 26.2 & 2.6 & 13.19 & 2.5 \\
13.86 & 2.6 & 27.94 & 2.4 & 13.53 & 2.5 \\
24.95 & 1.4 & 44.28 & 1.5 & 21.49 & 1.5 \\
26.86 & 1.3 & 55.9 & 1.2 & 26.16 & 1.3 \\
22.07 & 1.6 & 43.63 & 1.5 & 21.63 & 1.5 \\
26.02 & 1.4 & 51.42 & 1.3 & 23.86 & 1.4 \\
21.98 & 1.6 & 42.58 & 1.6 & 21.61 & 1.5 \\
29.6 & 1.2 & 59.09 & 1.1 & 28.54 & 1.2 \\
15.05 & 2.4 & 30.47 & 2.2 & 13.61 & 2.4 \\
18.71 & 1.9 & 39.29 & 1.7 & 18.2 & 1.8 \\
20.88 & 1.7 & 40.3 & 1.7 & 20.46 & 1.6 \\
21.84 & 1.7 & 40 & 1.7 & 19.97 & 1.7 \\
36.08 & original & 67.11 & Original & 33.17 & original \\
\hline
\end{tabular}

Statistical analysis of the lanthanide decontamination factors versus the input variables (sodium level, hydroxide ion concentration, etc.) revealed three variables that were statistically significant for the $\mathrm{La}, \mathrm{Nd}$, and $\mathrm{Ce} \mathrm{DF}$ with an additional variable near the $5 \%$ significance level. Sodium level, hydroxide ion concentration, and aluminum concentration proved significant for each of the lanthanide elements and temperature was nearly significant.

Figure 2 contains the graphical representations of the computer fit of a linear response model for the decontamination factors for neodymium. Sodium level and temperature exhibit negative relationships with the DF. Increased sodium level equates to increased ion strength of the solution. In these high salt solutions, it can become very difficult to hydrolyze the lanthanide ion from the organic chelant species. The temperature effect in the range of 35 to $75^{\circ} \mathrm{C}$ is very minimal and can be neglected. Estimates of the coefficients are shown in Table 6. 
Table 6. Statistical Analysis Results from Nd DFs in Phase 1 Tests

\begin{tabular}{lllll}
\hline Term & Estimate & Std Error & $\mathbf{t}$ Ratio & Prob $>|\mathbf{t}|$ \\
& & & & \\
Intercept & 3.44 & 0.60 & 5.77 & 0.0004 \\
$\mathrm{Na}+$ & -0.275 & 0.076 & -3.60 & 0.007 \\
$\mathrm{OH}-$ & 0.422 & 0.14 & 2.94 & 0.019 \\
$\mathrm{Al}$ & 1.75 & 0.46 & 3.81 & 0.005 \\
Temp & -0.005 & 0.003 & -1.85 & 0.010 \\
Sr(total) & -0.135 & 0.115 & -1.20 & 0.265 \\
Sr(conc) & 0.75 & 2.29 & 0.33 & 0.75 \\
Fe(total) & -0.013 & 0.0115 & -0.11 & 0.92 \\
Fe(conc) & -0.75 & 2.29 & -0.33 & 0.75 \\
& & & & \\
\hline
\end{tabular}

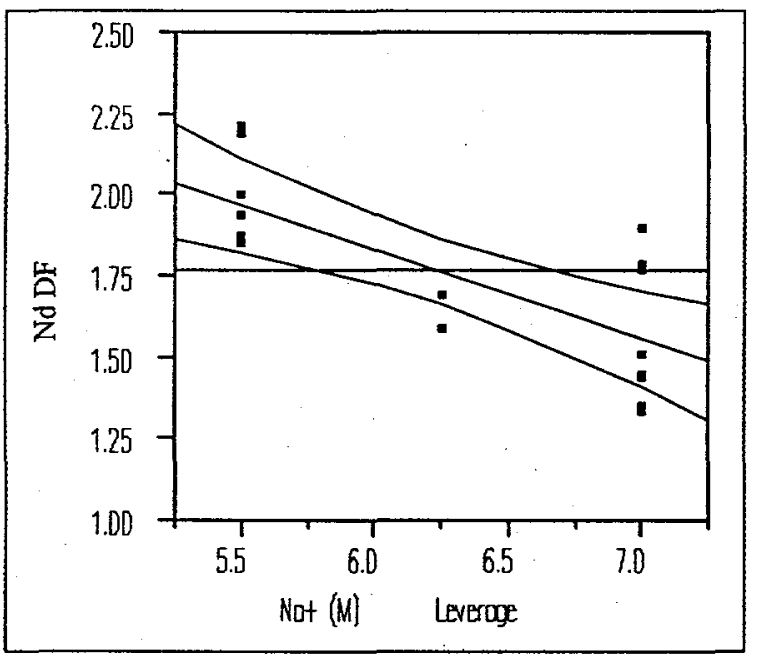

Figure 2. Neodymium DF as a Function of Sodium Level

Table 7 contains the aluminum concentrations measured in the post-precipitation liquid phase. Aluminum losses to the precipitate were very low. One sample, however, did exhibit a $10 \%$ reduction in aluminum concentration after precipitation. The sulfate level in 5 samples of the filtered solids was determined by ion chromatography. All solid samples exhibited measured concentrations of sulfate below the detection limit (20 $\mathrm{mg} / \mathrm{L}$ ). Total organic carbon measurements were obtained for the feed filtrate along with 
the post-precipitation filtrate from each beaker test. The data had very large fluctuations due to the large organic concentrations in the AN-107 simulant and were not meaningful.

Table 7. Al Concentrations $(\mathrm{mg} / \mathrm{L})$ in Phase 1 Tests

\begin{tabular}{ccc} 
Al & Al & Al \% \\
Measure after & $\begin{array}{c}\text { As } \\
\text { ppt }\end{array}$ & $\begin{array}{c}\text { prepared } \\
\text { in } \\
\text { ppt }\end{array}$ \\
1534.0 & 1575.7 & 97.4 \\
2052.0 & 1575.7 & 130.2 \\
8257.0 & 8279.8 & 99.7 \\
10640.0 & 8279.8 & 128.5 \\
1507.0 & 1535.5 & 98.1 \\
2085.0 & 1535.5 & 135.8 \\
9621.0 & 8229.7 & 116.9 \\
8253.0 & 8229.7 & 100.3 \\
1665.0 & 1645.6 & 101.2 \\
1966.0 & 1645.6 & 119.5 \\
7518.0 & 8330.8 & 90.2 \\
8854.0 & 8330.8 & 106.3 \\
1596.0 & 1614.5 & 98.9 \\
1956.0 & 1614.5 & 121.2 \\
7738.0 & 8301.0 & 93.2 \\
10250.0 & 8301.0 & 123.5 \\
5149.0 & 4965.4 & 103.7 \\
4938.0 & 4965.4 & 99.4 \\
& & \\
\hline & & \\
\hline & & \\
\hline
\end{tabular}

\subsection{Fe Titration}

With the results from the Phase 1 tests showing no variables affecting filterability, the simulant composition was determined questionable. In particular, the concentration of sodium gluconate, a known complexing agent for Fe (III), was suspected because it was based on process knowledge from the Pacific Northwest National Laboratory rather than analytical measurement. Therefore, experiments were performed to determine the maximum loading of the simulant for Fe (III) ions. The results of this iron titration are shown in Figure 3. 


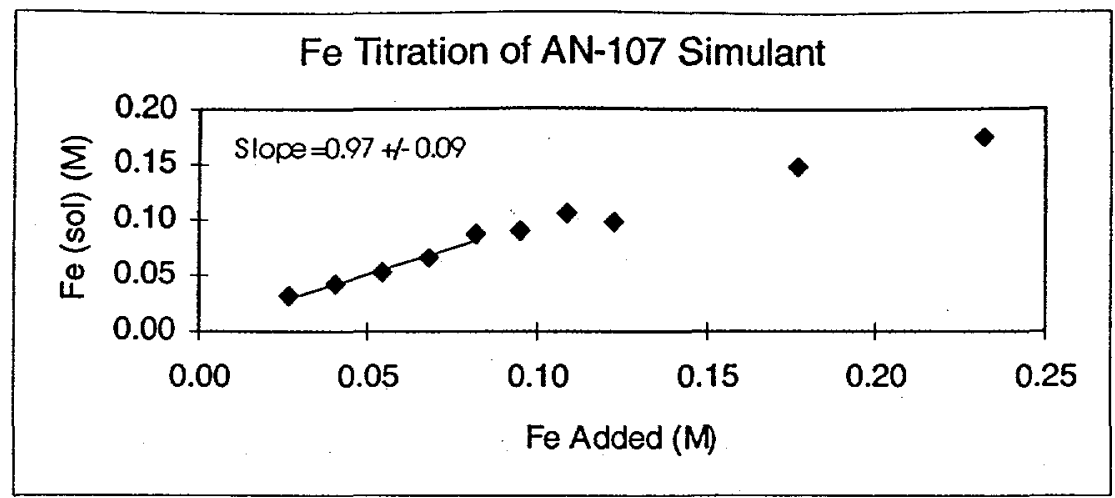

Figure 3. Fe Titration of AN-107 Simulant

For each addition of an aliquot of a $2 \mathrm{M} \mathrm{Fe}$ (III) nitrate solution, the measured iron concentration increased incrementally until the total added iron concentration was $0.1 \mathrm{M}$. The slope of the fitted line is 1 suggesting a 1:1 Fe:gluconate stoichiometry to the organometallic complex. The iron concentration in the real AN-107 waste is known to be $0.036 \mathrm{M}$. This titration data indicate the gluconate level should also be $0.036 \mathrm{M}$ rather than the $0.2 \mathrm{M}$ concentration currently used in the simulant. Because there exists a possibility that iron could exists as a 2:1 complex with gluconate, a simulant was prepared that contained sodium gluconate at $0.018 \mathrm{M}$ concentration and a second iron titration was preformed. The results are shown in Figure 4. As observed by $\mathrm{McCabe}^{2}$ in previous work, the iron concentration in the simulant decreased as ferric nitrate was added to the simulant. A red precipitate (FeOOH) was observed in each of the samples.

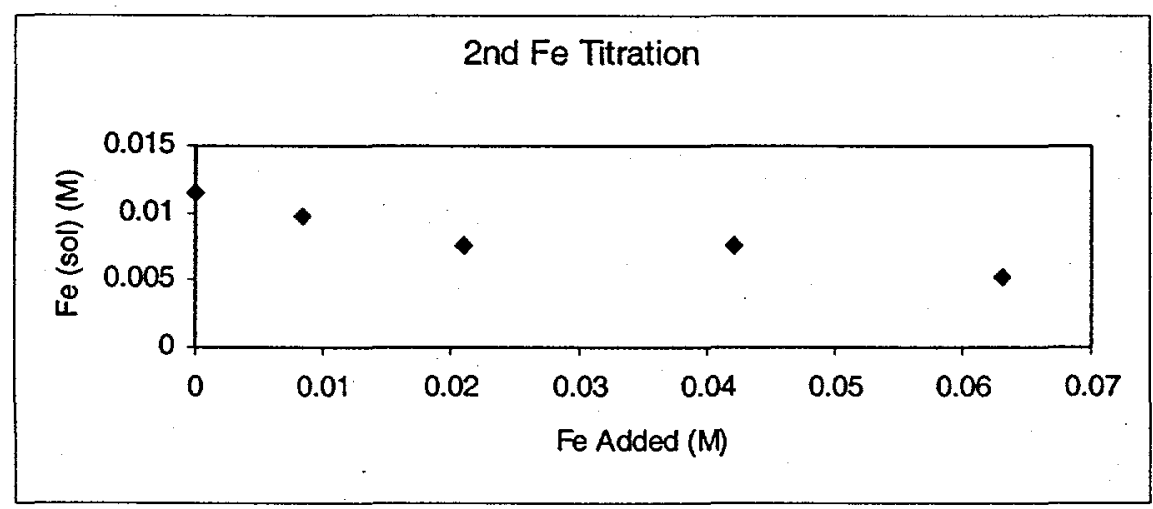

Figure 4. Fe Titration of Revised AN-107 Simulant

\subsection{Confirmatory Tests}

With the change to the gluconate concentration $(0.018 \mathrm{M})$ in the simulant formulation for the AN-107 tank, a set of confirmatory tests was conducted. The experimental matrix for 
this set of tests along with the measured filtrate flux is shown in Table 8. Several variables that had not shown to be influencing the decontamination process were deleted. Although temperature was a significant variable, the magnitude of the effect was negligible. Elemental analysis of the simulated supernate was performed pre- and postprecipitation. The resulting data were regressed using the JMP statistical analysis software. Figure 5 shows photographs of the starting filtrate, precipitation filtrate and the precipitate solids. The filtrate remains very dark in color after the precipitation. The precipitates are reddish to brown in color, indicating the presence of iron in the precipitate.

Table 8. Experimental Matrix for Confirmatory Tests

\begin{tabular}{|c|c|c|c|c|c|c|c|}
\hline Test No. & Pattern & $\mathrm{Na}+(\mathrm{M})$ & $\mathrm{OH}-(\mathrm{M})$ & $\mathrm{Al}(\mathrm{M})$ & $\operatorname{Sr}(M)$ & $\mathrm{Fe}(\mathrm{M})$ & $\begin{array}{c}\text { Filtrate Flux } \\
(\mathrm{g} / \mathrm{s})\end{array}$ \\
\hline 1 & --++ & 5.5 & 0.4 & 0.05 & 0.025 & 0.075 & 0.083 \\
\hline 2 & --++- & 5.5 & 0.4 & 0.3 & 0.075 & 0.025 & 0.128 \\
\hline 3 & -+-+- & 5.5 & 1 & 0.05 & 0.075 & 0.025 & 0.186 \\
\hline 4 & -++++ & 5.5 & 1 & 0.3 & 0.025 & 0.075 & 0.072 \\
\hline 5 & +-++ & 7 & 0.4 & 0.05 & 0.075 & 0.075 & 0.072 \\
\hline 6 & +-t-- & 7 & 0.4 & 0.3 & 0.025 & 0.025 & 0.128 \\
\hline 7 & ++- & 7 & 1 & 0.05 & 0.025 & 0.025 & 0.114 \\
\hline 8 & $++++t$ & 7 & 1 & 0.3 & 0.075 & 0.075 & 0.061 \\
\hline 9 & 00000 & 6.25 & 0.7 & 0.175 & 0.05 & 0.05 & 0.096 \\
\hline
\end{tabular}
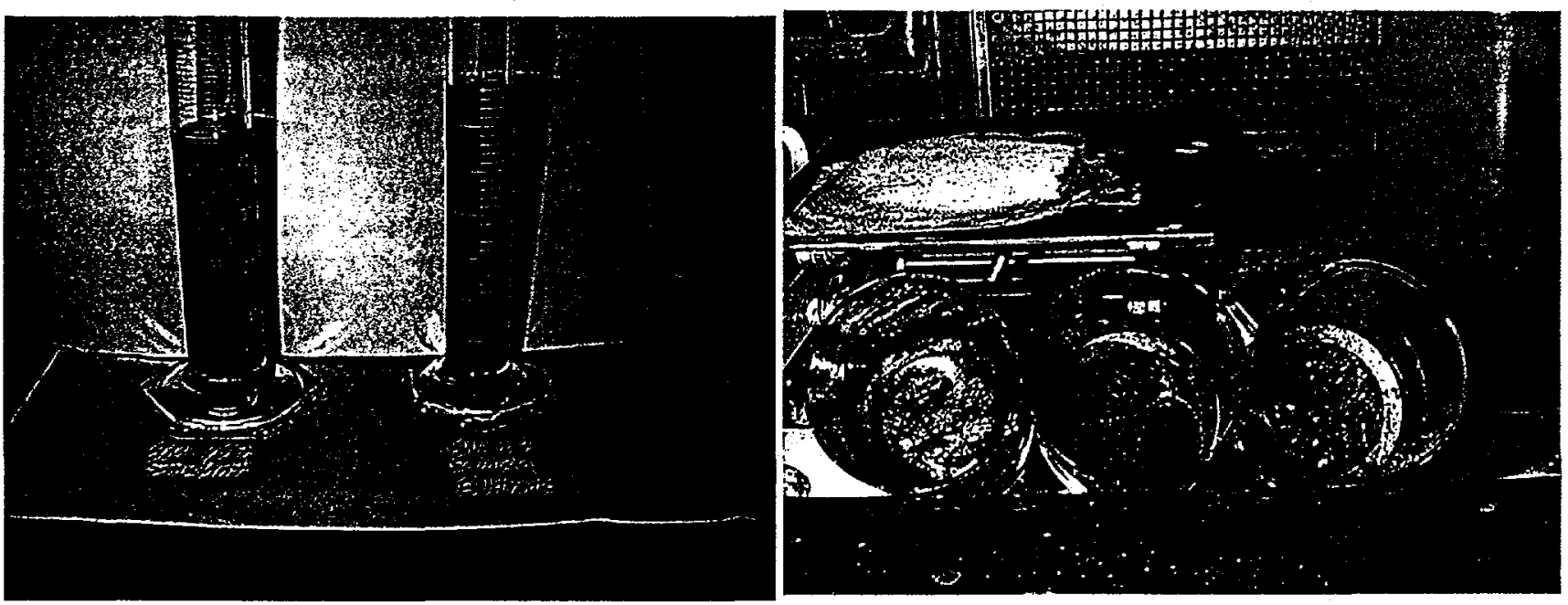

Figure 5. AN-102 Simulate Supernate, Sr/TRU Filtrate and Sr/TRU Precipitate

$\mathrm{JMP}^{\circledR}$ statistical analysis program was used to analyze the filtration data. Table 9 contains the results of the statistical analysis. As expect, the total iron concentration 
added to precipitate the lanthanide ions was statistically significant and a plot of this effect is shown in Figure 6. However, iron concentration was the only significant variable. Ionic strength (sodium level) and hydroxide ion concentration did not affect filterability. It had been previously believed that increased ionic strength (sodium level) would decrease the filterability and increased hydroxide ion concentration would increase filterability.

Table 9. Statistical Analysis of the Filtration Data from Confirmatory Tests

\begin{tabular}{lcrrl}
\hline & & & & \\
Term & Estimate & Std Error & t Ratio & Prob $>|t|$ \\
& & & & \\
Intercept & 15.8 & 4.1 & 3.83 & 0.03 \\
$\mathrm{Na}+(\mathrm{M})$ & -0.94 & 0.6 & -1.55 & 0.22 \\
$\mathrm{OH}-(\mathrm{M})$ & 0.42 & 1.13 & 0.37 & 0.73 \\
$\mathrm{Al}(\mathrm{M})$ & -3.9 & 3.6 & -1.07 & 0.36 \\
Sr conc (M) & 15.4 & 18.1 & 0.85 & 0.46 \\
Fe conc (M) & -80.2 & 18.1 & -4.42 & 0.02 \\
& & & \\
\hline
\end{tabular}

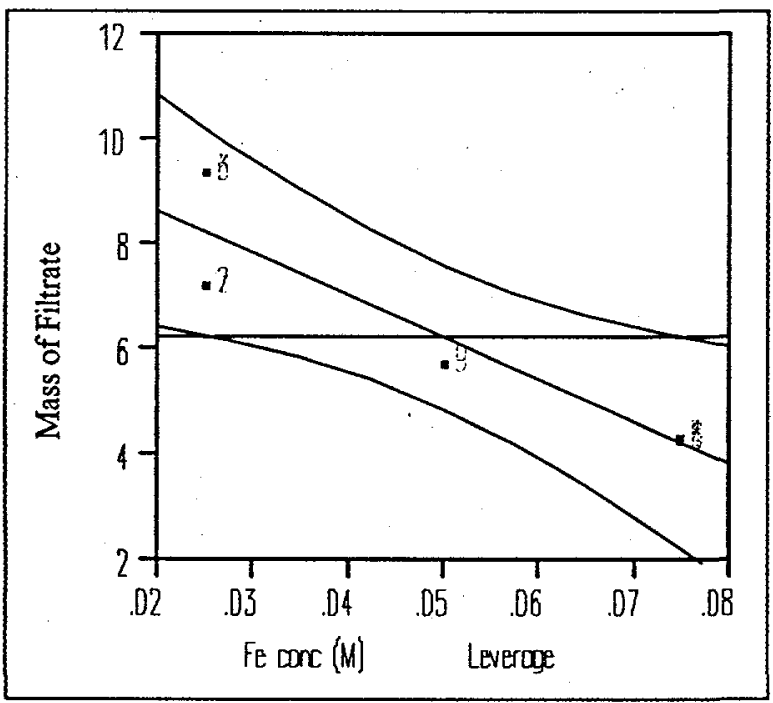

Figure 6. Filtrate Mass versus Iron Concentration in Confirmatory Tests

Table 10 contains the lanthanide concentrations measured in the precipitation tests with the revised AN-107 simulant. The process decontamination factors (DFs) include the ionic strength and caustic adjustments. The DFs for the lanthanide elements ranged from $2-7.2,2-6.3$ and $1.8-6$ for lanthanum, cerium and neodymium, respectively. This 
trend of lower DFs for Nd compared to La has been observed in several scoping studies performed at SRTC and may be indicative of the increased charge density on the Nd ion.

Table 10. Lanthanide Concentrations $(\mathrm{mg} / \mathrm{L})$ in Confirmatory Tests

\begin{tabular}{|c|c|c|c|c|c|c|c|c|c|}
\hline \multirow[b]{2}{*}{ Test No. } & \multicolumn{3}{|c|}{ Initial } & \multicolumn{3}{|c|}{ Post } & \multicolumn{3}{|c|}{$\mathrm{DF}^{*}$} \\
\hline & $\mathrm{La}$ & $\mathrm{Ce}$ & Nd & $\mathrm{La}$ & $\mathrm{Ce}$ & $\mathrm{Nd}$ & $\mathrm{La}$ & $\mathrm{Ce}$ & $\mathrm{Nd}$ \\
\hline 1 & 23.02 & 22.5 & 42.76 & 7.167 & 7.135 & 18.03 & 5.3 & 5.4 & 3.8 \\
\hline 2 & 18.83 & 18.72 & 34.21 & 6.246 & 6.589 & 19.73 & 6.1 & 5.8 & 3.5 \\
\hline 3 & 21.44 & 19.73 & 37.88 & 10.18 & 11.46 & 30.82 & 3.7 & 3.3 & 2.2 \\
\hline 4 & 27.29 & 14 & 15.07 & 5.288 & 6.091 & 15.32 & 7.2 & 6.3 & 4.5 \\
\hline 5 & 29.27 & 27.76 & 51.95 & 9.25 & 9.077 & 23.59 & 4.1 & 4.2 & 2.9 \\
\hline 6 & 17.08 & 1.475 & 26.52 & 17.6 & 18.1 & 38.89 & 2.2 & 2.1 & 1.8 \\
\hline 7 & 24.92 & 23.88 & 45.54 & 17.32 & 19.01 & 39.01 & 2.2 & 2.0 & 1.8 \\
\hline 8 & 32.93 & 19.18 & 17.15 & 8.184 & 8.933 & 23.4 & 4.6 & 4.3 & 3.0 \\
\hline $9 * *$ & 22.33 & 38.3 & 21.15 & 10.91 & 28.1 & 11.63 & 3.5 & 1.4 & 6.0 \\
\hline Stock & 38.01 & 38.2 & 69.26 & & & & & & \\
\hline
\end{tabular}

*DF $=[$ stock $] /[$ post $]$

**Test 9 was a mid point test

Statistical analysis of the DF data is provided in Table 11. There are some differences between results for each of the lanthanide elements; however, the effect of each of the variables is the same. In the lanthanum results, sodium level was statistically significant at a $5 \%$ significance level and iron concentration was nearly significant. The magnitude of the effect for each of these variables is shown in Figure 7 and was as expected. Sodium ion increases resulted in a slight decrease in the DF (estimate of slope of DF vs $[\mathrm{Na}]=-1.5$ ). An increase in iron concentration showed a large increase in the DF (estimate of DF vs [Fe] = 35). Additionally, hydroxide ion did not have an effect on the DF obtained for lanthanum, neodymium, or cerium.

The results for cerium and neodymium are not statistically significant but the estimates from the fitted models support the same conclusion. In the results for cerium DF, there were no statistically significant variables. However, the magnitudes of the estimates are nearly identical to those for lanthanum. In the neodymium results, there are no significant effects and the estimates are slightly different but of the same direction. This delta for neodymium may be indicative of its higher charge density due to its smaller size.

The results of these tests indicate that successful decontamination of the actinide surrogates ( $\mathrm{La}, \mathrm{Ce}$, and $\mathrm{Nd}$ ) can be obtained. The optimum conditions would be to utilize 
W. R. Wilmarth

high concentrations of ferric nitrate $(0.075 \mathrm{M})$ and with low sodium ion concentration $(5.5 \mathrm{M})$. These results agree with those obtained with radioactive samples of AN-107 performed by McCabe. ${ }^{5}$

Table 11. Statistical Analysis Result from the Confirmatory Tests

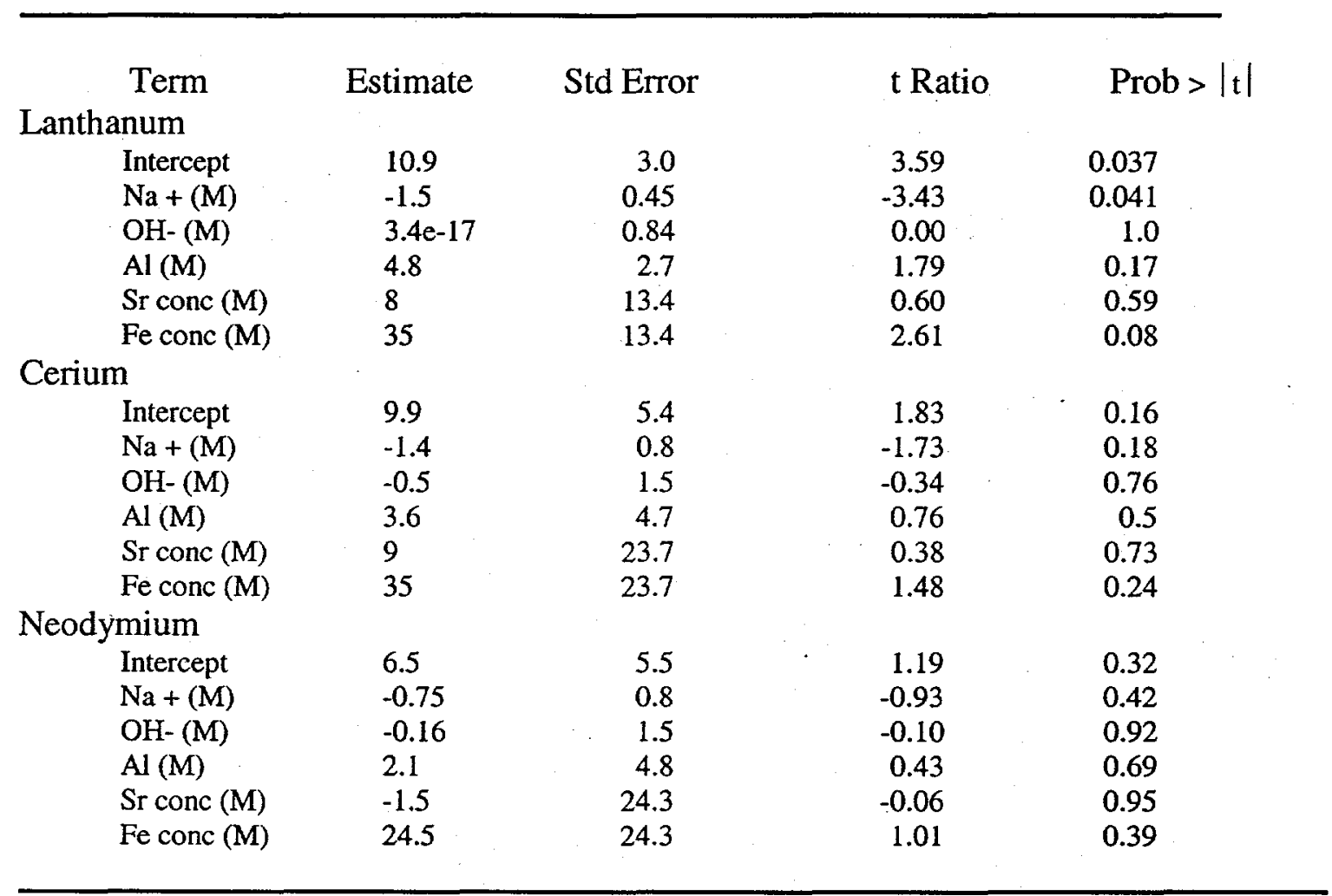

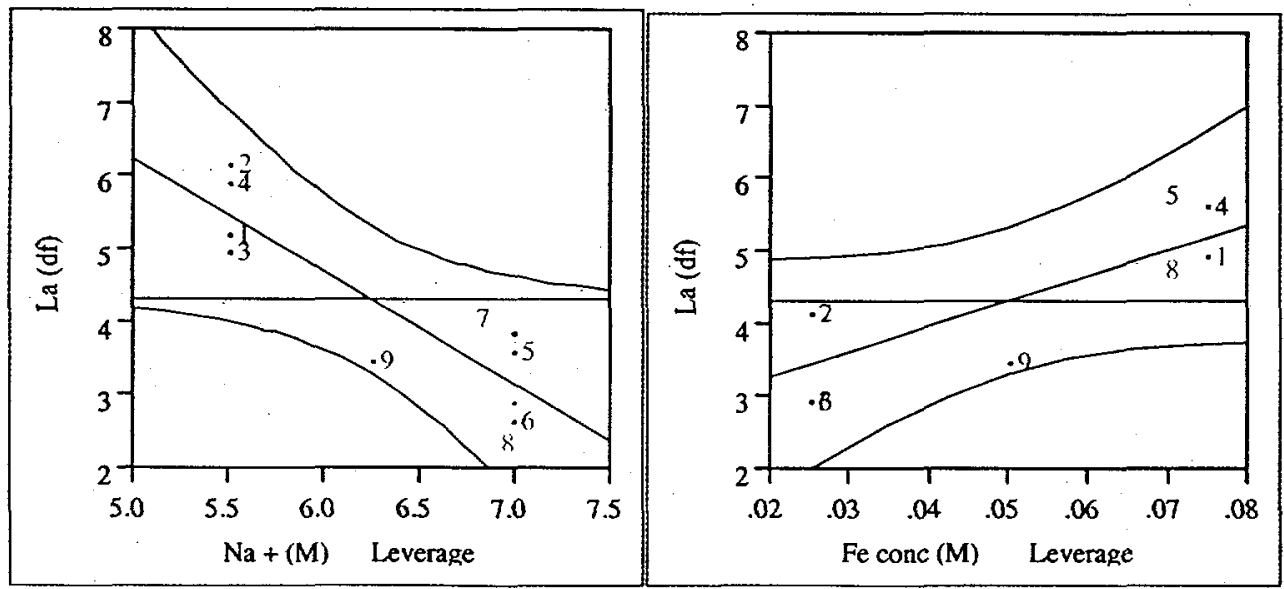

Figure 7. Sodium and Iron Statistical Plots for DF in Confirmatory Tests 


\subsection{Organic Grouping Single Effects Tests}

The purpose of the Phase 2 tests was to further investigate the variables shown in Phase 1 tests to affect filterability and DF and to estimate the effects of the various organic complexing agents. In order to minimize the number of variables, the organic complexing agents were grouped into three groupings based on their chemistries. The EDTA group was comprised of EDTA, HEDTA, NTA, and IDA. These complexing agents are derivatives of the same function group and typically target divalent cations. Gluconate was placed into a separate group because of its affinity for the trivalent iron species. Thus, the last group of organic complexing agents contained glycolate and citrate. Three scoping tests were performed to determine the magnitude of the effects these groups had on the filterability. The test conditions were: $5.5 \mathrm{M} \mathrm{Na}, 1.0 \mathrm{M} \mathrm{OH}, 0.4$ $\mathrm{M} \mathrm{Al}, 0.075 \mathrm{M} \mathrm{Sr}$ and $\mathrm{Fe}$ and $50^{\circ} \mathrm{C}$. Shown in Table 12 are the results of Sr/TRU precipitation tests with the three organic complexant groups. Also included is the result from the AN-107 simulant. The data are displayed in Figure 8.

\section{Table 12. Organic Group Single Effects Tests}

\begin{tabular}{lccc}
\hline & Filtrate & Filtrate & Flux \\
& Mass $(\mathrm{g})$ & Flux $(\mathrm{g} / \mathrm{s})$ & $\begin{array}{c}\text { (gpm/ft2) } \\
\text { EDTAHHEDTANTAIDA }\end{array}$ \\
Glycolate/Citrate & 3.795 & 0.063 & 0.038 \\
Gluconate & 14.649 & 0.244 & 0.148 \\
AN-107 Simulant & 17.541 & 0.292 & 0.177 \\
& 3.685 & 0.061 & 0.037 \\
\hline
\end{tabular}

The filtrate flux measured in the three experiments ranged from 0.063 to $0.292 \mathrm{~g} / \mathrm{s}$ compared to the flux of $0.061 \mathrm{~g} / \mathrm{s}$ measured for the AN-107 simulant. The precipitate from the glycolate and citrate group simulant filtered nearly as well as the precipitate from the gluconate-containing simulant. These results agree with the low complexing ability of citrate and glycolate. The results from the gluconate test agree with the results from the Phase 1 tests previously reported. The EDTA/HEDTA/NTA/IDA-containing simulant filtered very poorly almost identically to the AN-107 simulant containing all of the organic complexing agents. These results suggest incorporation of some organic material into the $\mathrm{Sr} / \mathrm{Fe}$ precipitate. This organic material could help blind the filter lowering the filtrate flux. With these results, the seven organic complexants have been separated into two groups: group 1 consisting of EDTA/HEDTA/NTA/IDA and group 2 consisting of Glycolate/Citrate/Gluconate. 


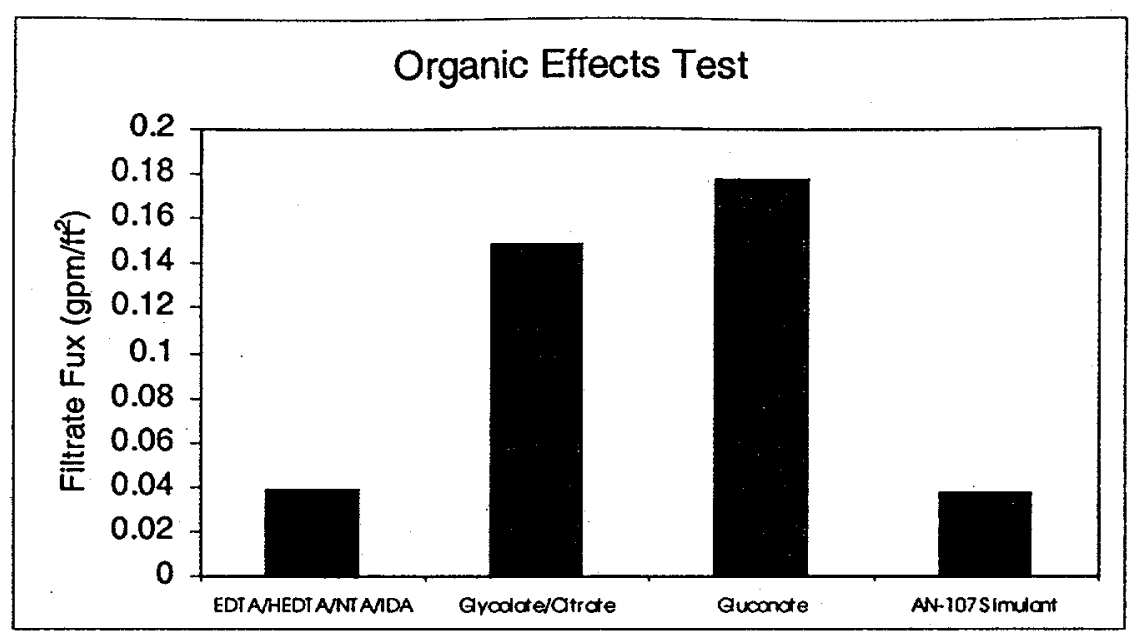

Figure 8. Filtrate Flux Results from Organic Grouping Tests

\subsection{Real Waste Scoping Tests}

In order to test the filterability of the sample of AN-102 supernate and compare this to the AN-107 simulant filterability results, three Sr/TRU precipitation tests were performed. In the first test, ferric nitrate was added to a $0.75 \mathrm{M}$ concentration followed by the addition of strontium nitrate to the same concentration. This is the order of addition used in previous testing ${ }^{8}$ that proved un-filterable. The second test reversed the order of addition ( $\mathrm{Sr}$ followed by $\mathrm{Fe}$ ) that was used in the other tests reported herein. Lastly, a test was performed which examined the effect of shear on the filterability of the Sr/TRU precipitate formed by strontium addition followed by iron addition.

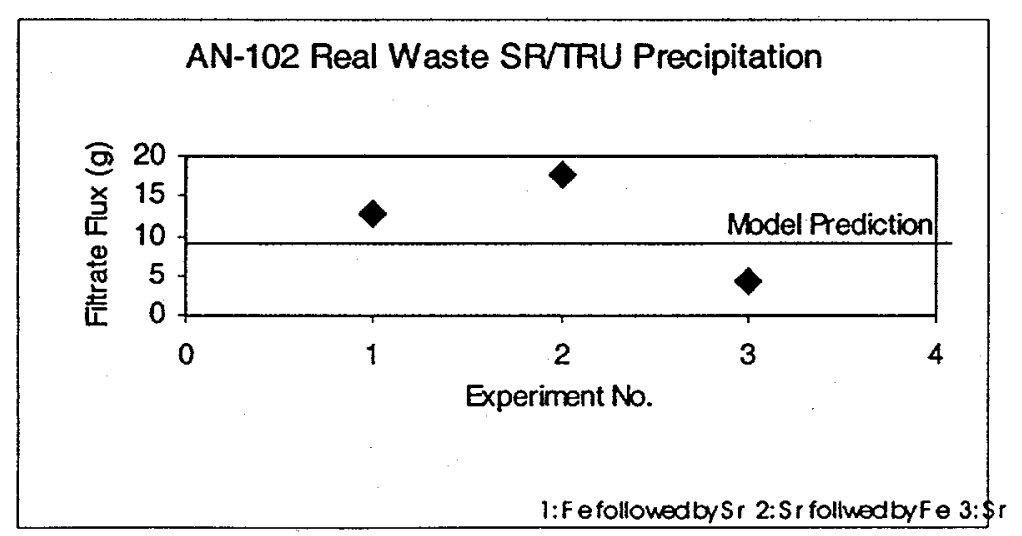

Figure 9. Filtration Data from Real Waste Tests with AN-102 Samples 
The filtration data from the real waste scoping tests are shown in Figure 9. The measured filtrate mass from the first and second tests exceed the model developed for the AN-107 simulant. The reverse order of addition of the precipitating agents caused an increase in the amount of filtrate. The third test examined the effect of shear on the filterability of the $\mathrm{Sr} / \mathrm{TRU}$ precipitate. It was expected that the filtrate flux would be reduced due to the shearing forces in the blender. The filtrate flux was reduced from $0.3 \mathrm{~g} / \mathrm{s}$ to $0.07 \mathrm{~g} / \mathrm{s}$. The filtration performance of this sample of AN-102 supernate is greatly increased over that of the previous sample during Part A. ${ }^{2}$

While the filterability of the AN-102 sample was very encouraging, the results from the Sr-90 and actinide analyses were not. Shown in Table 13 are the measured decontamination factors (DFs) for the radionuclides of interest. McCabe ${ }^{2}$ had previously measured DFs in a sample from AN-102.

Table 13. DFs from Real Waste Tests of AN-102

\begin{tabular}{cccc}
\hline Test & Sr-90 & Pu-239 & Am-241 \\
1 & 31 & 1.03 & 1.3 \\
2 & 37 & 1.5 & 2.1 \\
3 & 40 & 1.4 & 2.1 \\
Required & 6 & 1.0 & 1.25 \\
DF & 200 & 1.6 & $1.9-2.1$ \\
McCabe $^{2}$ & 200 & & \\
\hline
\end{tabular}

The data from both sets of experiments agree fairly well with the exception of the DF for Sr-90. McCabe added strontium to a concentration of $0.1 \mathrm{M}$ while the current tests utilized $0.075 \mathrm{M}$ strontium. Other differences between the experimental conditions are the current tests used a $6.8 \mathrm{M}$ sodium ion concentration prior to the hydroxide adjustment, and McCabe started with a $5.5 \mathrm{M}$ sodium ion concentration. McCabe reported that the resulting americium concentration $(0.032 \mu \mathrm{Ci} / \mathrm{mL})$ in the supernate was below the acceptance limit; whereas, the Am concentration $(0.075 \mu \mathrm{Ci} / \mathrm{mL})$ is above the limit $(100 \mathrm{nCi} / \mathrm{g})$ for the tests reported herein.

\subsection{Phase 2 (25 Beaker) Tests}

In the Phase 2 tests, simulated AN-107 waste was spiked with $\mathrm{Sr}-85, \mathrm{Am}-241$ and $\mathrm{Pu}-239$ radio-tracers on the order of $10^{5} \mathrm{dpm} / \mathrm{mL}$. Various levels of organic complexing agents were added according to the experimental matrix. The effects of these organic agents on the filterability of the Sr/TRU precipitation process were examined along with the 
decontamination of the radio-tracers. Three other variables were studied and were the sodium, aluminum, and hydroxide concentrations.

The results of the filtration tests are shown in Table 14. Filtrate volume was measured after one minute in the Phase 2 studies instead of the filtrate mass due to contamination control measures. Filtrate volumes ranged from $0 \mathrm{~mL}$ to $32.3 \mathrm{~mL}$. In general, the filterability of the precipitates formed in this phase was poor. The filtration data shows six conditions in which little or filtrate was obtained. These conditions span the sodium and hydroxide conditions used in the tests. Additionally, the mid point filtration data showed a very low filtrate flux of $0.05 \mathrm{~g} / \mathrm{s}$.

The filtration data was regressed using the JMP software. Table 15 contains the results of this regression. The concentration of the gluconate group agents was shown to be a statistically significant variable. The group of complexing agents included gluconate, glycolate, and citrate. This group had a negative impact on filterability, i.e., increased level decrease filterability. This result is somewhat surprising since increased gluconate levels increases the solubility of iron and should have provided for better filtration

\section{Table 14. Filtrate Volumes* from Phase 2 Beaker Tests}

\begin{tabular}{|c|c|c|c|c|c|c|c|c|}
\hline Pattern & Test No. & $\mathrm{Na}$ & $\mathrm{OH}$ & Al. & $\mathrm{Fe}$ Conc & EDTA Gp. & Gluconate & $\begin{array}{l}\text { Filtrate vo } \\
\text { (mL) }\end{array}$ \\
\hline .......- & 1 & 5.5 & 0.4 & 0.05 & 0.02 & -1 & -1 & 19.5 \\
\hline---++++ & 2 & 5.5 & 0.4 & 0.05 & 0.1 & 1 & 1 & 1 \\
\hline-++++ & 3 & 5.5 & 0.4 & 0.3 & 0.02 & -1 & 1 & 0 \\
\hline-++-+ & 4 & 5.5 & 0.4 & 0.3 & 0.1 & 1 & -1 & 19 \\
\hline++-++ & 5 & 5.5 & 1 & 0.05 & 0.02 & 1 & -1 & 32.3 \\
\hline+++-+ & 6 & 5.5 & 1 & 0.05 & 0.1 & -1 & 1 & 1 \\
\hline++++ & 7 & 5.5 & 1 & 0.3 & 0.02 & 1 & 1 & 1 \\
\hline++++ & 8 & 5.5 & 1 & 0.3 & 0.1 & -1 & -1 & 16.4 \\
\hline$+\cdots++$ & 9 & 7 & 0.4 & 0.05 & 0.02 & 1 & 1 & 0 \\
\hline++++ & 10 & 7 & 0.4 & 0.05 & 0.1 & -1 & -1 & 9.4 \\
\hline++++ & 11 & 7 & 0.4 & 0.3 & 0.02 & 1 & -1 & 7.2 \\
\hline++++- & 12 & 7 & 0.4 & 0.3 & 0.1 & -1 & 1 & 10 \\
\hline++++ & 13 & 7 & 1 & 0.05 & 0.02 & -1 & 1 & 0 \\
\hline+++-+ & 14 & 7 & 1 & 0.05 & 0.1 & 1 & -1 & 7.2 \\
\hline$++\cdots+$ & 15 & 7 & 1 & 0.3 & 0.02 & -1 & -1 & 5.3 \\
\hline+++++++ & 16 & 7 & 1 & 0.3 & 0.1 & 1 & 1 & 0 \\
\hline 000000 & 17 & 6.25 & 0.6 & 0.175 & 0.06 & 0 & 0 & 2.9 \\
\hline $00000^{*}$ & 18 & 6.25 & 0.6 & 0.175 & 0.075 & 0 & 0 & 3.3 \\
\hline
\end{tabular}

${ }^{F}$ Volumes measured after one minute filtration.

performance with corresponding reduction in the TRU DF. The citrate component should not have an effect; however, glycolate could potentially act as a surfactant. The 
concentration of the gluconate group spanned the concentrations of thee organic species in the real AN-102 and AN-107 wastes. This action could peptize the precipitate.

Additionally, the sodium level was significant, but only at a $10 \%$ level. The Phase 2 data model predicts poorer filterability at high sodium levels. This is indicative of the high ionic strength of the solution. Shown in Figure 10 are the statistical plots for gluconate group and sodium levels. This data clearly indicates the glycolate/gluconate concentrations present in the real $\mathrm{AN}-102$ and $\mathrm{AN}-107$ wastes will affect the filterability of the ferric hydroxide precipitate. Without removal of the glycolate/gluconate, the ferric hydroxide precipitate can not be filtered in the AN-102 and AN-107 solutions.

\section{Table 15. Regression Results from Phase 2 Filtration Tests}

\begin{tabular}{lllll}
\hline & & & & \\
Term & Estimate & Std Error & $\mathrm{t}$ Ratio & Prob $>|\mathrm{t}|$ \\
Intercept & 35.4 & 15.6 & 2.27 & 0.04 \\
Sodium & -4.3 & 2.3 & -1.83 & 0.09 \\
Hydroxide & 0.007 & 5.77 & 0.00 & 0.99 \\
Aluminum & -5.75 & 13.9 & -0.41 & 0.69 \\
Fe Conc. & -4.5 & 43.4 & -0.10 & 0.92 \\
EDTA Gp & 0.38 & 1.7 & 0.22 & 0.83 \\
Gluconate Gp & -6.45 & 1.7 & -3.7 & 0.0035 \\
\end{tabular}
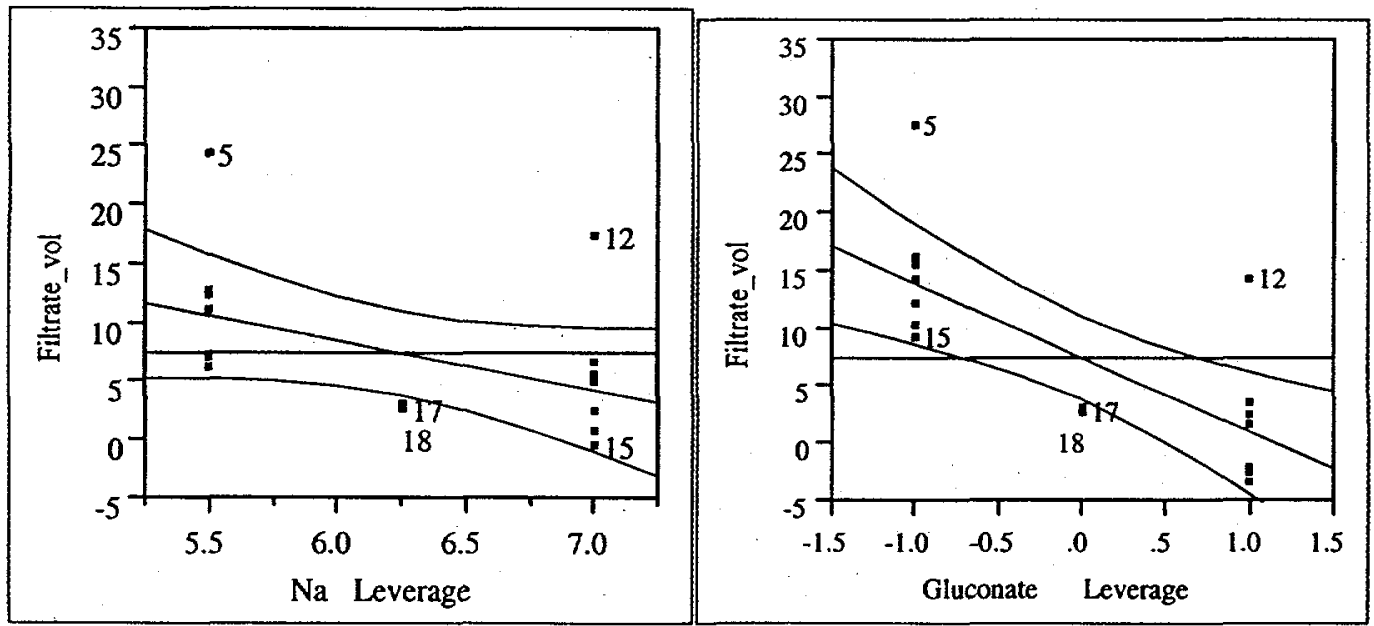

Figure 10. Statistical Plot for the Gluconate Group and the Sodium Levels 


\section{Table 16. Decontamination Factors from Phase 2 Tests}

\begin{tabular}{|c|c|c|c|c|}
\hline Pattern & Test No. & Sr DF & Am & $\mathrm{Pu}$ \\
\hline$\ldots . . .$. & 1 & 32.2 & & 6.6 \\
\hline-++++ & 2 & 29.3 & 1.5 & 2.2 \\
\hline+++++ & 3 & 37.8 & 3.0 & 1.3 \\
\hline$+++\cdots++$ & 4 & 10.0 & 1.4 & 5.6 \\
\hline+++++ & 5 & 7.5 & 3.3 & 2.4 \\
\hline+++++ & 6 & 13.2 & 1.4 & 1.2 \\
\hline+++++ & 7 & 4.8 & 1.0 & 1.0 \\
\hline$+++1+$ & 8 & 39.2 & & \\
\hline$++1+$ & 9 & 10.8 & 1.3 & 1.7 \\
\hline$+\cdots++\cdots$ & 10 & 52.6 & & 3.6 \\
\hline++++ & 11 & 4.5 & 1.5 & 4.6 \\
\hline++++ & 12 & 24.0 & 2.9 & 1.3 \\
\hline$++\cdots+$ & 13 & 15.7 & 0.9 & 11.9 \\
\hline+++-+ & 14 & 32.9 & 1.8 & 1.0 \\
\hline$+H+\cdots+$ & 15 & 26.6 & & 1.0 \\
\hline$+H+1+t+$ & 16 & 14.3 & 1.4 & 1.3 \\
\hline 000000 & 17 & 21.2 & 2.3 & 3.3 \\
\hline $00000^{*}$ & 18 & 17.0 & 1.3 & 1.4 \\
\hline
\end{tabular}

Table 16 compiles the decontamination factors (DFs) neglecting the effect of dilution obtained in the Phase 2 tests for Sr-85, PAM-241, and Pu-239. The starting, spiked concentrations were nominally $10^{4} \mathrm{dpm} / \mathrm{mL}$. The DFs for Sr ranged from 4.5 to 52.6 . The DFs for the actinides ranged from 1 to 3 for Am and 1 to 12 for Pu. The DFs measured for americium are not sufficient to operate the proposed flowsheet which requires the Am-241 DF to be greater than 1.25 not including dilution. The DFs for $\mathrm{Sr}$ and Pu provide sufficient decontamination of the supernate.

Regression of DF data for strontium revealed only one statistically significant variable, the concentration of the EDTA group. An increase in the concentration of the EDTA group (EDTA, HEDTA, IDA, and NTA) caused a decrease in the DF for strontium. Figure 12 displays the statistical plot of the strontium DF data. Strontium is known to complex with EDTA and the other members of this organic grouping. Because only a single level of non-radioactive strontium was added in these tests, the data imply that some of this strontium was complexed by the chelants. This would effectively lower the isotope dilution effect of adding non-radioactive strontium.

Conversely, the statistical analysis of the actinide DF data did not reveal any variable as significant. Even iron concentration was not significant indicating a very large experimental error. Any experimental error could mask the effects of the process variables. If the response (DF) was larger than measured, then perhaps the effect each variable has could be measured. The low DFs for Am and the inability to measure an iron concentration effect are very detrimental to this flowsheet. 


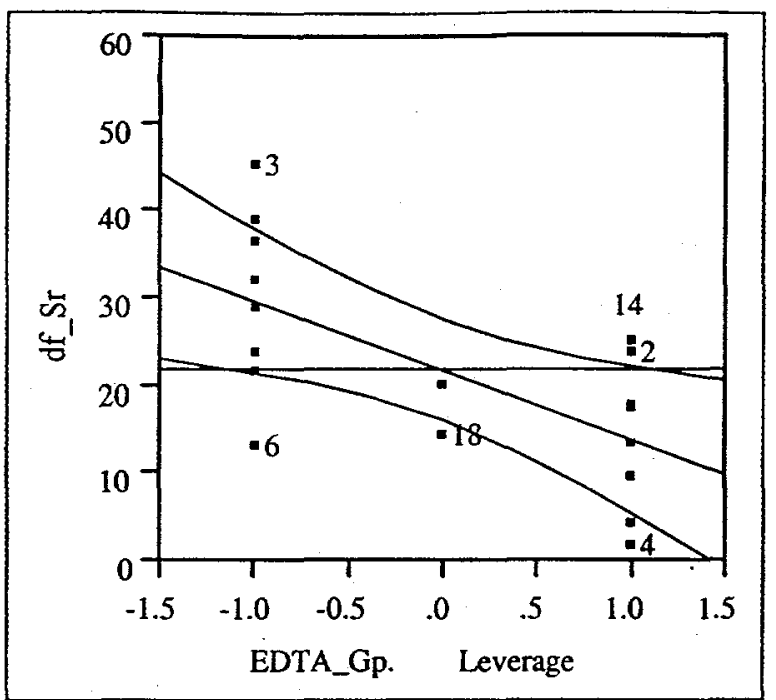

Figure 11. Statistical Plot of Sr DF Data

\subsection{Conclusions}

Approximately a dozen variables have been examined for their influence on the proposed Sr/TRU decontamination process for the tanks AN-102 and AN-107 in the BNFL flowsheet. Three sets of statistically designed experiments have evaluated these variables under non-radioactive and radioactive conditions. Additionally, a set of tests using a sample from $\mathrm{AN}-107$ was performed to assess the flowsheet on real waste.

The combined results of the statistically designed testing and the single effect testing for improved filterability of the resultant precipitate demonstrate the importance of three variables. Although no variable was statistically significant in the Phase 1 tests with simulant enriched in gluconate, the sodium level was important in the confirmatory tests and the Phase 2 tests. The effect was a reduction in filterability at higher sodium levels and the magnitude of the effect was comparable in both sets of tests. The variable with the largest detrimental effect on filterability is the concentration of ferric nitrate added to co-precipitate the actinide ions. In order to obtain acceptable filter performance, the amount of ferric nitrate added would be insufficient to remove the required amount of actinide ion for further processing. Additionally, the results from the Phase 2 tests indicate a member of the gluconate grouping of complexing agents is also detrimental to the filterability of the Sr/TRU precipitate. It is believed that the glycolate ion is in large enough concentration to cause the precipitate to peptize; thus, reducing the filterability. Visual observations of the precipitation indicate a change in the nature of the precipitate. Initially, the precipitate is discrete particles. Prior to filtration the precipitate appears more like a gel with less particulate features. 
The results for the factors affecting decontamination are not as conclusive but show some agreement to the factors found effecting filterability. Increased sodium levels were detrimental to lanthanide decontamination in the Phase 1 and the confirmatory tests. The largest single variable affecting lanthanide decontamination was, as expected, the amount of ferric nitrate added. This effect was exhibited in the confirmatory tests. However, sufficient decontamination factors could not be obtained in any of the series of tests including the real waste tests. These real waste tests exhibited better filterability than previously observed and acceptable decontamination of radio-strontium. However, plutonium and americium DFs were marginally acceptable at maximum ferric nitrate addition.

Overall, the process and chemical variables are better understood following these series of tests. The improved baseline flowsheet for Sr/TRU removal is still insufficient in the two responses of interest, filterability and decontamination. Alternative precipitating agents such as other transition metals or oxidants should be examined to replace the ferric nitrate co-precipitation of the actinide ions.

\subsection{Acknowledgements}

The authors wish to acknowledge the help and assistance provided by the Analytical Development Section in their analysis of the many samples submitted during this work. Additionally, Vicki Dukes in the preparation and handling of the samples performed an excellent job.

\subsection{References}

1. M. J. Klein and W. G. Wilson, " Strontium Recovery from Purex Acidified Sludge," ARH-CD-691, May 1976.

2. D. J. McCabe, "Hanford Envelope Archive C Tank Waste Precipitation Study (U)," SRTC-BNFL-004, Revision 0, March 20, 1997.

3. D. J. McCabe, "Hanford C Tank Waste Precipitation Study (U)," SRTC-BNFL-005, Rev. 2, August 13, 1997.

4. D. J. McCabe, "Hanford Simulant Tank Waste Precipitation Study," SRTC-BNFL006, Rev. 0, April 22, 1997.

5. D. J. McCabe, "Hanford Envelope C Tank Waste Precipitation Optimization Study (U)," SRTC-BNFL-011, Rev. 0, August 13, 1997.

6. D. L. Herting, "Report of Scouting Study on Precipitation of Strontium, Plutonium and Americium from Hanford Complexant Concentrate Waste," WHC-SD-WMDTR-040, Rev. 0, 1995. 
7. R. J. Orth, A. H. Zacher, A. J. Schmidt, M. R. Elmore, K. R. Elliott, G. G. Neuenschwander, S. R. Gano, "Removal of Strontium and Tranuranics from Hanford Tank Waste via Addition of Metal Cations and Chemical Oxidant - FY1995 Test Results," PNL-10766, UC-721, September, 1995.

8. C. A. Nash, WSRC Invention Disclosure, SRS-98-0061, June 25, 1998.

9. W. R. Wilmarth, C. A. Nash, and T. B. Edwards, "Task Technical and Quality Assurance Plan for Sr/TRU Precipitation of Hanford High Level Waste," BNF-00398-0012, Rev. 0, October 14, 1998.

10. W. R. Wilmarth, "Preliminary Results of Rate of Delivery Experiments for Envelope C Simulant”, BNF-003-98-0023, November 5, 1998.

11. "Obtaining Analytical Services, "Manual L1, Procedure 3.07, Rev. 0, August 6, 1993.

12. "Inductive Coupled Plasma - Emission Spectrometer for Aqueous Liquid Sample Analysis," Manual L16.1, Procedure ADS-1509, June 25, 1996.

13. "Inductively Coupled Plasma - Mass Spectrometer Elemental and Isotopic Analysis for Aqueous Liquid Sample Fisons PlasmaQuad II (U)," Manual L16.1, Procedure ADS1543, Rev. 1, April 1, 1998.

14. "Gamma Sample Preparation and Analysis (Gamma PHA)," Manual L16.1, Procedure ADS-2420, Rev. 3, July 28, 1997.

15. "Beta Liquid Scintillation Sample Preparation and Analysis," Rev. 3, Manual L16.1, Procedure 2401, March 20, 1997.

16. "Alpha Pulse Height Analysis," Manual L16.1, Procedure ADS-2402, Rev. 2, July $25,1994$.

17. SAS Institute, Inc., "JMP Statistics and Graphic Guide," Version 3, SAS Institute, Inc., Cary, NC, 1994.

18. Statistical Consulting Section, "Software Verification and Validation for Commercial Statistical Packages Utilized by the Statistical Consulting Section of SRTC," WSRCRP-99-00422, Rev. 0, May 21, 1999. 
$\therefore \vdots \quad$.W. R. Wilmarth

BNF-003-98-0180

8.0 Approvals:

Page 31 of 33

Author

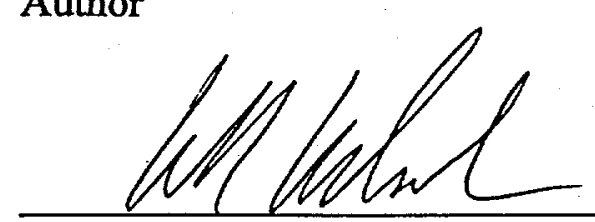

W. R. Wilmarth Waste Processing Technology

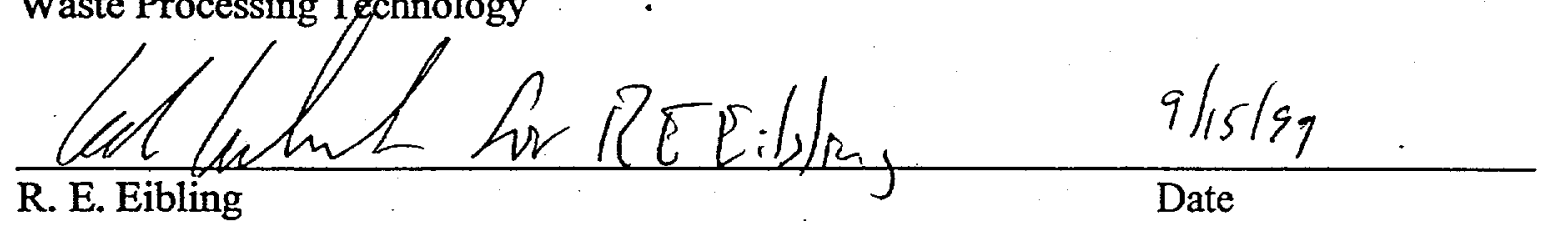

Immobilization Technology

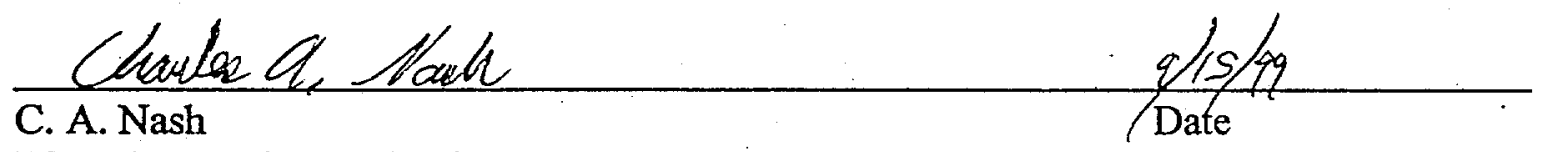

Waste Processing Technology

Thomas B Edward

T. B. Edwards Statistical Consulting Section

Design Check

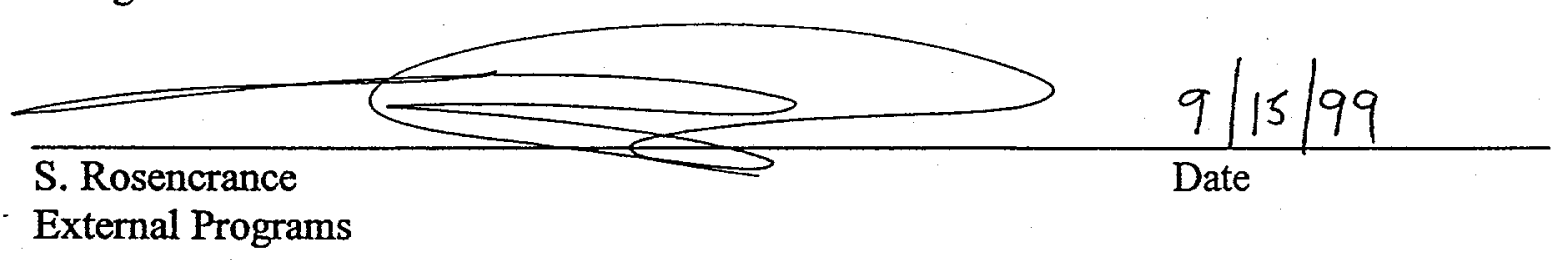

Management

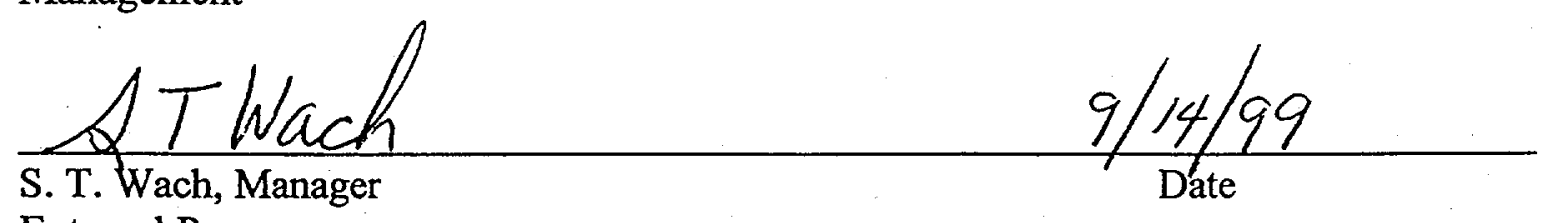

External Programs 
Appendix 1. AN-107 Simulant Composition

\begin{tabular}{|c|c|c|c|c|}
\hline Component & Molecular weight & Concentration & Concentration & Units \\
\hline Acetate & 59.04462 & $1100 \mathrm{mg} / \mathrm{Liter}$ & $1.86 \mathrm{E}-02$ & $2 \mathrm{M}$ \\
\hline Aluminum & 26.98154 & $386 \mathrm{mg} /$ Liter & $1.43 \mathrm{E}-02$ & $2 \mathrm{M}$ \\
\hline Ammonium & 18.03846 & $22 \mathrm{mg} /$ Liter & $1.22 \mathrm{E}-0$ & $3 M$ \\
\hline Barium & 137.33 & $7 \mathrm{mg} /$ Liter & $5.42 \mathrm{E}-0 \leqslant$ & $5 \mathrm{M}$ \\
\hline Boron & 10.81 & $35 \mathrm{mg} /$ Liter & $3.24 \mathrm{E}-0$ & $3 M$ \\
\hline Bromide & 79.904 & $1150 \mathrm{mg} /$ Liter & $1.44 \mathrm{E}-02$ & $2 \mathrm{M}$ \\
\hline Cadmium & 112.41 & $64 \mathrm{mg} /$ Liter & $5.70 \mathrm{E}-0$ & $4 \mathrm{M}$ \\
\hline Calcium & 40.08 & $591 \mathrm{mg} /$ Liter & $1.47 \mathrm{E}-02$ & $2 \mathrm{M}$ \\
\hline Carbonate & 60.0092 & $83936 \mathrm{mg} / \mathrm{Liter}$ & $1.40 E+O C$ & $10 \mathrm{M}$ \\
\hline Cerium & 140.12 & $53 \mathrm{mg} /$ Liter & 3.77E-0 & $4 M$ \\
\hline Chloride & 35.453 & $1830 \mathrm{mg} /$ Liter & $5.16 \mathrm{E}-02$ & $2 \mathrm{M}$ \\
\hline Chromium & 51.996 & $176 \mathrm{mg} / \mathrm{Liter}$ & 3.38E-03 & $3 \mathrm{M}$ \\
\hline Copper & 63.546 & $30 \mathrm{mg} /$ Liter & 4.74E-0 & $4 M$ \\
\hline $\begin{array}{l}\text { Ethylenediaminete } \\
\text { traacetic acid }\end{array}$ & 288.20824 & $5620 \mathrm{mg}$ /Liter & $1.95 \mathrm{E}-02$ & $12 M$ \\
\hline Fluoride & 18.9984 & $133 \mathrm{mg} / \mathrm{Liter}$ & $7.00 \mathrm{E}-0$ & $3 M$ \\
\hline Formate & 45.01774 & $10400 \mathrm{mg} / \mathrm{Liter}$ & 2.31E-0 & $1 M$ \\
\hline Glycolate & 75.04206 & $18600 \mathrm{mg} / \mathrm{Liter}$ & $2.48 \mathrm{E}-0$ & $1 \mathrm{M}$ \\
\hline Hydroxide & 17.00734 & $340 \mathrm{mg} /$ Liter & $2.00 \mathrm{E}-02$ & $2 M$ \\
\hline Iron & 55.847 & $1690 \mathrm{mg} /$ Liter & $3.03 E-02$ & $2 \mathrm{M}$ \\
\hline Lanthanum & 138.9055 & $46 \mathrm{mg} / \mathrm{Liter}$ & $3.28 \mathrm{E}-0$ & $4 M$ \\
\hline Lead & 207.2 & $388 \mathrm{mg} /$ Liter & $1.87 \mathrm{E}-0$ & $3 M$ \\
\hline Magnesium & 24.305 & 25 mg/Liter & $1.03 \mathrm{E}-0$ & $3 M$ \\
\hline Manganese & 54.938 & $563 \mathrm{mg} / \mathrm{Liter}$ & $1.02 \mathrm{E}-0$ & $2 M$ \\
\hline Molybdenum & 95.94 & $36 \mathrm{mg} /$ Liter & 3.73E-0 & $4 \mathrm{M}$ \\
\hline Neodymium & 144.24 & $96 \mathrm{mg} /$ Liter & $6.65 \mathrm{E}-0$ & $4 \mathrm{M}$ \\
\hline $\begin{array}{l}\text { n- } \\
\text { Hydroxyethylenedi } \\
\text { aminetriacetic acid }\end{array}$ & 275.23618 & $2140 \mathrm{mg} / \mathrm{Liter}$ & $7.78 \mathrm{E}-0$ & $3 \mathrm{M}$ \\
\hline Nickel & 58.69 & $530 \mathrm{mg} /$ Liter & $9.03 E-0$ & $3 \mathrm{M}$ \\
\hline Nitrate & 62.0049 & $230000 \mathrm{mg} / \mathrm{Liter}$ & $3.71 E+0$ & $10 \mathrm{M}$ \\
\hline Nitrite & 46.0055 & $61000 \mathrm{mg} /$ Liter & $1.33 E+0$ & $10 \mathrm{M}$ \\
\hline Oxalate & 88.0196 & $826 \mathrm{mg} /$ Liter & $9.38 E-0$ & $3 M$ \\
\hline Phosphate & 94.97136 & $1110 \mathrm{mg} / \mathrm{Liter}$ & 1.17E-0: & $2 \mathrm{M}$ \\
\hline Potassium & 39.0983 & $1810 \mathrm{mg} / \mathrm{Liter}$ & 4.63E-0 & $2 \mathrm{M}$ \\
\hline Selenium & 78.96 & $1 \mathrm{mg} /$ Liter & $6.33 \mathrm{E}-06$ & $6 \mathrm{M}$ \\
\hline Silicon & 28.0855 & \#VALUE! & \#VALUE! & $M$ \\
\hline Silver & 107.8682 & $14 \mathrm{mg} / \mathrm{Liter}$ & $1.33 \mathrm{E}-0$ & $4 \mathrm{M}$ \\
\hline Sodium & 22.9898 & $195000 \mathrm{mg} / \mathrm{Liter}$ & $8.48 \mathrm{E}+0$ & $0 M$ \\
\hline Sulfate & 96.0576 & $8250 \mathrm{mg} / \mathrm{Liter}$ & $8.59 \mathrm{E}-0$ & $2 M$ \\
\hline TIC & 12.011 & $16800 \mathrm{mg} / \mathrm{Liter}$ & $1.40 \mathrm{E}+\mathrm{O}$ & $0 \mathrm{M}$ \\
\hline TOC & & $40400 \mathrm{mg} / \mathrm{Liter}$ & 40.4 & $10 \mathrm{~g} / \mathrm{L}$ \\
\hline Uranium & & 127 mg/Liter & $1.27 \mathrm{E}+0$ & $2 \mathrm{ug} / \mathrm{mL}$ \\
\hline Zinc & 65.38 & 45 mg/liter & $6.93 E-0$ & $4 M$ \\
\hline Zirconium & 91.22 & 70 mg/Liter & 7.67E-0 & $4 M$ \\
\hline
\end{tabular}


W. R. Wilmarth

BNF-003-98-0180

Page 33 of 33

Additional Organics(based upon PNNL Report on FY1997 Results)

Nitrilotriacetic Acid $\quad 188.11618$

Citric Acid

189.09618

$561 \mathrm{mg} /$ Liter

$8495 \mathrm{mg} / \mathrm{Liter}$

2.98E-03 M

4.49E-02 $M$

4.54E-02 $M$

Source Previous PNNL Recipe

Sodium Gluconate

218.14

$43628 \mathrm{mg} / \mathrm{Liter}$

2.00E-01 M 